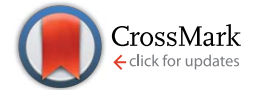

Cite this: RSC Adv., 2017, 7, 7442

Received 1st November 2016 Accepted 21st December 2016

DOI: $10.1039 / c 6 r a 26124 h$

www.rsc.org/advances

\section{Recent advances in the synthesis, functionalization and biomedical applications of hydroxyapatite: a review}

\begin{abstract}
Adnan Haider, ${ }^{\text {ab }}$ Sajjad Haider, ${ }^{c}$ Sung Soo Han ${ }^{\text {b }}$ and Inn-Kyu Kang*a
Hydroxyapatite (HA) is a member of the Ca apatite family. It resembles natural bone in both structure and chemical composition. HA, owing to its bioactive and biocompatible properties, has been commonly used as an implant material in bone tissue regeneration (osteogenesis), and as a drug carrier in drug and gene delivery systems. With the advances in research on the use of $\mathrm{HA}$, an increasing number of researchers are exploring new synthesis processes, characterization and functionalization techniques for HA and its potential role in various fields such as magnetic resonance, controlled delivery of therapeutic drugs, cell separation, bio imaging and treatment of hyperthermia. Therefore, in this review, we highlight the composition of $\mathrm{HA}$, the advances in its synthesis processes, characterization and functionalization techniques, and its importance in the biomedical field in general, and in emerging areas such as implants, drug delivery, composites, coatings, and ceramic materials in particular. The idea behind writing this review was to collect and summarize the most recent studies involving HA, so that researchers can easily find HA-related information compiled in a single document. In addition, we have also discussed the future prospects of $\mathrm{HA}$. We believe that readers will not only conveniently obtain the desired information from this review, but will also get to the core of the information more easily.
\end{abstract}

${ }^{a}$ Department of Polymer Science and Engineering, School of Applied Chemical Engineering, Kyungpook National University, Daegu 702-701, Republic of Korea. E-mail: ikkang@knu.ac.kr

${ }^{b}$ Biomaterials Lab, Department of Nano, Medical \& Polymer Materials, College of Engineering, Yeungnam University, 280 Daehak-ko, Gyeongsan, Gyeongsanbukdo 712-749, Korea

${ }^{c}$ Department of Chemical Engineering, College of Engineering, King Saud University, P.O. Box 800, Riyadh 11421, Saudi Arabia

\section{Introduction}

Knowledge regarding the structure and composition of natural bone from the macro to the nanoscale has been acquired in a stepwise manner. ${ }^{1}$ Ancient civilizations lacked sufficient knowledge about the nature of bone and used bone as a fine tool. Concrete information about natural bone became clearer

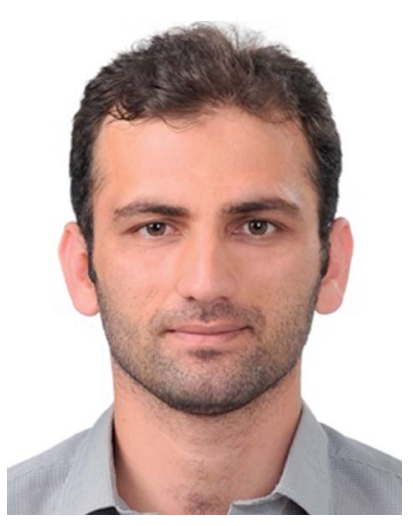

Dr Adnan Haider is a Post Doc Research Fellow at Nano, Medical and Polymer materials Department, School of Chemical Engineering, Yeungnam University Daegu South Korea. He received his MSc degree in 2010 from Kohat University of Science and Technology, Kohat, Pakistan. MS integrated PhD degree in 2016 from the Department of Polymer Science and Engineering, Kyungpook National University, Daegu, South Korea. His research work focuses on the development of biopolymer composites for tissue regeneration, and fabrication of electrospun nanofibers for their biomedical and environmental applications.

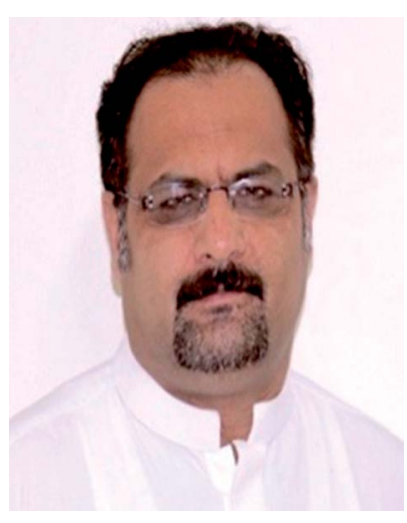

Dr Haider is an assistant professor at the Chemical Engineering Department, King Saud University, Riyadh, Saudi Arabia since May 2009. He received his MSc degree in 1999. MPhil in 2004 from the Institute of Chemical Sciences, University of Peshawar, KPK, Pakistan and PhD degree in 2009 from the Department of Polymer Science and Engineering, Kyungpook National University, Daegu,

South Korea. His research work focuses on the development of carbon nanotubes and biopolymer composites, polymer hydrogel actuators, and preparation of the electrospun nanofibers for environmental and biomedical applications. 
with the emergence of microscopic techniques. ${ }^{2}$ With the advances in microscopy, we can now study bone at the microscale level. Research is currently being conducted to study bone at the nanoscale level, and more specifically, at the basic unit or building block level (which is called collagen fibril). One of the difficulties in studying bone at the nanoscale level is the extremely small size of the bone crystals, which can be as smaller as a few nanometers in width and thickness. ${ }^{3}$ Therefore, bone crystals are the smallest crystals formed biologically. Bone has a hierarchically ordered structure, which is similar to that of

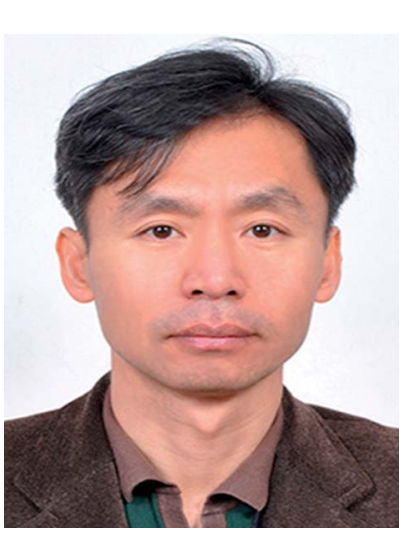

Sung Soo Han is a professor at Nano, Medical and Polymer Materials Department, Yeungnam Univeristy, Daegu South Korea. He got his Ph.D. degree from Department of Polymer and Textile Engineering, Seoul, Seoul National University in 1994. He has published various research articles under reputed publishers. His research work focuses on preparation of scaffolds for tissue regeneration, textiles, synthesis of nanoparticles and their role in drug delivery, hydrogels packs for skin care, polymer composite. other biological structures such as the intestine, muscles, etc. ${ }^{3,4}$ The lowest stage of this hierarchy is the uniform, and highly ordered arrangement of HA nanocrystals in collagen fibrils (Fig. 1). Depending on the nature and shape of the bone; nanocrystals are arranged in a highly ordered manner in the collagen fibril, either in a lamellar or in a layer-by-layer form. The HA nanocrystals are arranged in such a manner that the $c$-axes of the HA nanocrystals are oriented along the fibril axes (Fig. 1). ${ }^{4}$

Chemically, HA is a naturally occurring mineral form of calcium (Ca) apatite (apatite: group of phosphate minerals). Hence, calcium phosphates and its derivatives are of great interest to various fields of science such as biology, medicine, chemistry, and geology. The attempts to determine their chemical structure and composition started in the middle of the $18^{\text {th }}$ century. However, it was Hausen in the $19^{\text {th }}$ century who proposed the existence of different calcium phosphate phases (earlier all calcium phosphates were called apatites). Among the various calcium phosphates, HA is extremely important owing to its structural and chemical similarities to bone phosphates. In addition, $\mathrm{HA}$ is the most stable derivative of calcium phosphate salts within the $\mathrm{pH}$ range of 4-14 at room temperature. ${ }^{7}$ It is owing to these properties that HA has found numerous applications in the fields of protein chromatography, fertilizers, pharmaceuticals, water treatment, and biomedicine..$^{7,8}$

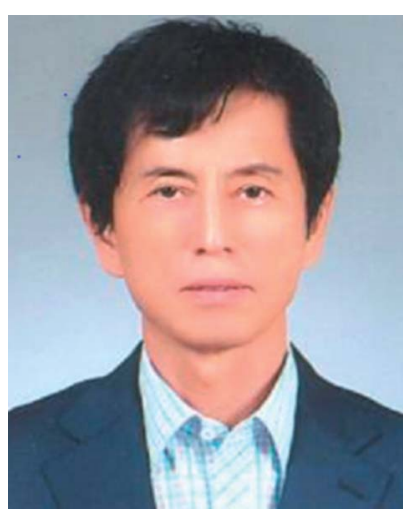

Inn-Kyu Kang is a professor in the Department of Polymer Science and Engineering at the School of Applied Chemical Engineering, Graduate School, Kyungpook National University. He obtained his Ph.D. degree in Polymer Chemistry at Kyoto University in 1987, and joined in the Department of Polymer Science and Engineering in 1988 as a professor. He is currently a fellow in the International Union of Society for Biomaterials Science and Engineering. He has published more than 215 articles and his research is focused on surface modification, nanofiber scaffolds, functionalization of nanoparticles, and liquid crystal biosensors. Comment: During last one decade several advancements have been made in fabrication of scaffolds for tissue engineering using various techniques of fabrication and materials of different origin. The scaffolds for tissue engineering are ranging from nanofibers to nanoparticles and have been developed by tuning their morphology and architecture. Several breakthroughs have been reported and successful attempts have been made to overcome the drawbacks of the scaffolds fabricated by conventional and modern methods of scaffolds formation yet significant amount of research is required to control the vascularity of the scaffolds, which is a major challenge in the field of fabrication of scaffolds for bone tissue engineering. Although few attempts have been made by harvesting cells from donor/patient to vascularize the scaffolds before their implantation in the patient but area still need intensive research to develop scaffolds with proper vascularization. The worldwide research has achieved success in tissue engineering but matrix induced autologus condrocyte implantation has received little success in repair of cartilage. The bioactivity of scaffolds totally depends on surface topology, microstructure, chemistry and mechanical properties of scaffolds. Thus controlling the cells behavior and remodelling is a critical step in development of next generation scaffolds for tissue engineering. The functionalized scaffolds loaded with certain amount of growth factor and therapeutics to stimulate cells proliferation and treatment of infection after surgical operations also strongly needed to achieve success in the area of tissue engineering and regeneration. The increasing interest to incorporate a drug delivery function in the scaffolds is emerged as a new field of scaffolds engineering. The drug loaded scaffolds are able to provide sufficient amount of drug at a specific place in comparison to systematic drug delivery systems. The scaffolds loaded with growth factors such as cytokines, hormones, morphogens and proteins need to be developed to enhance cells adhesion, proliferation and differentiation in tissue engineering. The mechanical behavior of scaffolds has important implication on tissue regeneration; stiff scaffolds mimic pre calcified bone and elastic scaffolds mimic the elasticity of muscles, which cause mesenchymal stem cell differentiation down to a myogenic pathway. Thus scaffolds with optimized mechanical strength need to be fabricated for enhanced bone tissue engineering. The critical review of the literature reported during last one decade has clearly indicated that there is lot of scope to improve the properties and functionality of the scaffolds for bone tissue engineering using various biomaterials and their fabrication techniques. 


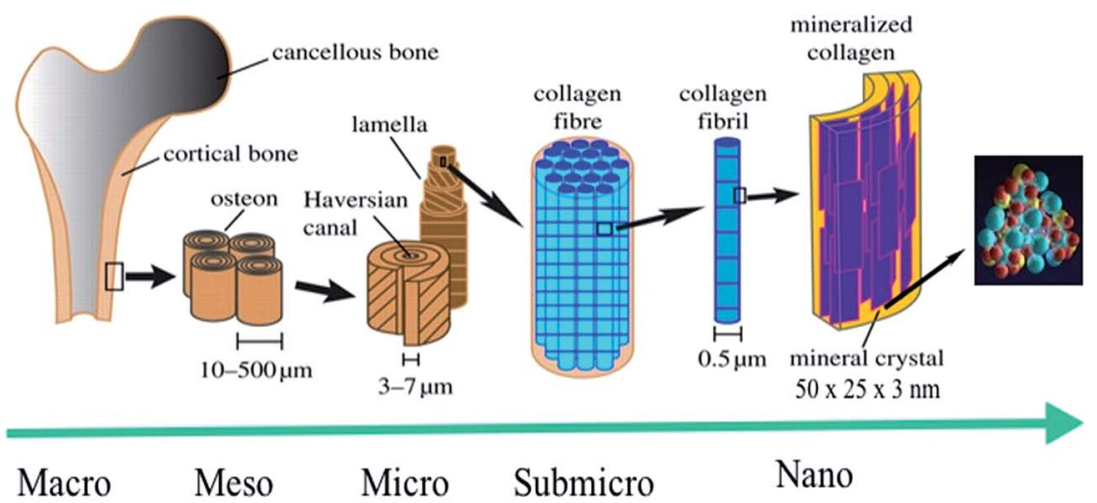

Fig. 1 Hierarchical structure of bone at various size scales. The microstructure of cortical bone consists of osteons with Haversian canals and lamellae, whereas at the nanoscale, the structural units are collagen fibers composed of bundles of mineralized collagen fibrils (this figure was modified from the work of Zhang et al. and Rho et al.). ${ }^{5,6}$

HA has found broad applications in the biomedical field ${ }^{7}$ owing to its bioactive and biocompatible nature. It has been frequently used in bone tissue regeneration. Several researchers have reported enhanced osteogenesis using HA. ${ }^{7}$ In addition to enhancing osteogenesis and acting as an implanting material, HA has been commonly used as a coating material as well. HA is usually coated on the surface of the implanting materials to enhance their bioactivity. Furthermore, HA is also a suitable material for carrying drugs (specially proteins) to the targeted sites, or for a slow and sustained release of drugs, which will ultimately help in stimulating the growth of osteoblastic cells. ${ }^{910}$ Owing to its wide range of applications in the biomedical field, and more specifically in bone tissue regeneration (osteogenesis), HA has been under intense study and several researchers have published their findings on the use of HA in various reputed journals and conference proceedings (Fig. 2). Therefore, the aim of this review is to compile all the information related to $\mathrm{HA}$, discuss and summarize it in a structured manner, and provide future prospects, so that readers can easily access the desired information.

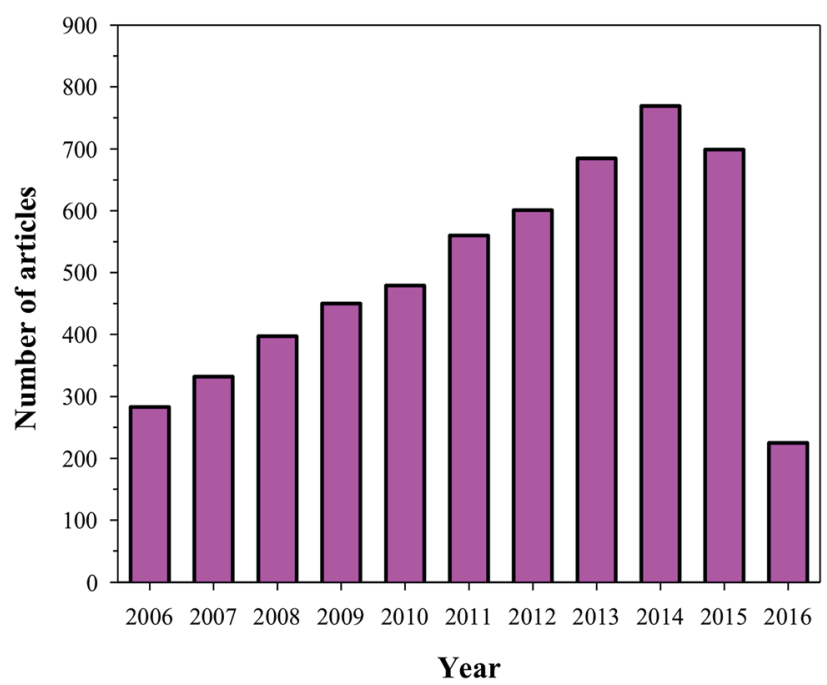

Fig. 2 Articles indexed in Scopus from 2006 to 2016 with HA.

\subsection{Chemical composition and synthesis of HA}

As mentioned earlier, HA is a member of the apatite family (consists of $\mathrm{Ca}$ and phosphates) with the general formula $\mathrm{Ca}_{5}\left(\mathrm{PO}_{4}\right)_{3} \mathrm{OH}$, and unit cell formula $\mathrm{Ca}_{10}\left(\mathrm{PO}_{4}\right)_{6}(\mathrm{OH})_{2}$. In the unit cell of $\mathrm{HA}, \mathrm{Ca}$ and phosphates are arranged in such a manner that four $\mathrm{Ca}$ atoms are surrounded by nine $\mathrm{O}$ atoms of the phosphate moieties at the M1 position, and the other six Ca atoms are surrounded by the remaining six $\mathrm{O}$ atoms of the phosphate moieties at the M2 position. M1 and M2 are the crystallographic positions for all $\mathrm{Ca}$ atoms (Fig. 3)., ${ }^{4,11,12}$ Regardless of its origin, HA contains traces of impurities such as phosphite ions $\left(\mathrm{PO}_{3}{ }^{3-}\right)$, chloride ions $\left(\mathrm{Cl}^{-}\right)$, fluoride ions $\left(\mathrm{F}^{-}\right)$, and hydroxyl ions $\left(\mathrm{OH}^{-}\right) \cdot \mathrm{PO}_{3}{ }^{3-}$ and $\mathrm{Cl}^{-}$have been reported to weaken the HA structure, whereas $\mathrm{F}^{-}$and $\mathrm{OH}^{-}$are known to enhance the apatite strength.

Owing to the importance of HA in bone tissue regeneration and as a drug delivery material, various techniques have been reported for the preparation of HA nanoparticles and nanorods. Particle size and morphology are two important factors for suitable biomedical applications of HA. ${ }^{13}$ High emphasis has been placed on both HA synthesis and particle size, but very few reports are available on the morphology control of HA. The techniques commonly used for the preparation of HA particles include chemical precipitation (CP), ${ }^{14,15}$ hydrothermal (HT), ${ }^{16,17}$ electrospinning (ES), ${ }^{18}$ electrospraying (ESp), ${ }^{19}$ solid state (SS), ${ }^{14,15,20,21}$ microwave irradiation (MI), ${ }^{22-24}$ self-propagating combustion (SPC), ${ }^{25}$ emulsion and microemulsion (EMe), ${ }^{26}$ surfactant-assisted precipitation, ${ }^{24,27-29}$ chemical vapor, ${ }^{29}$ and flux cooling (FC) ${ }^{30}$ All these methods used for the preparation of HA particles result in different morphologies (Table 1) and chemical compositions. ${ }^{31}$ The number of annual publications using these methods is shown in Fig. 4. As observed from the figure, the most commonly used methods for the synthesis of HA are CP, HT, and sol-gel (SG). However, the preparation of HA nanoparticles with the right stoichiometry, high aspect ratio, and high crystallinity remains difficult to obtain. Conventional wet mechano-chemical methods are able to control the stoichiometry of the final product. In these methods, precursor solutions of $\mathrm{Ca}_{3}\left(\mathrm{PO}_{4}\right)_{2}$ and $\mathrm{Ca}(\mathrm{OH})_{2}$, are co- 

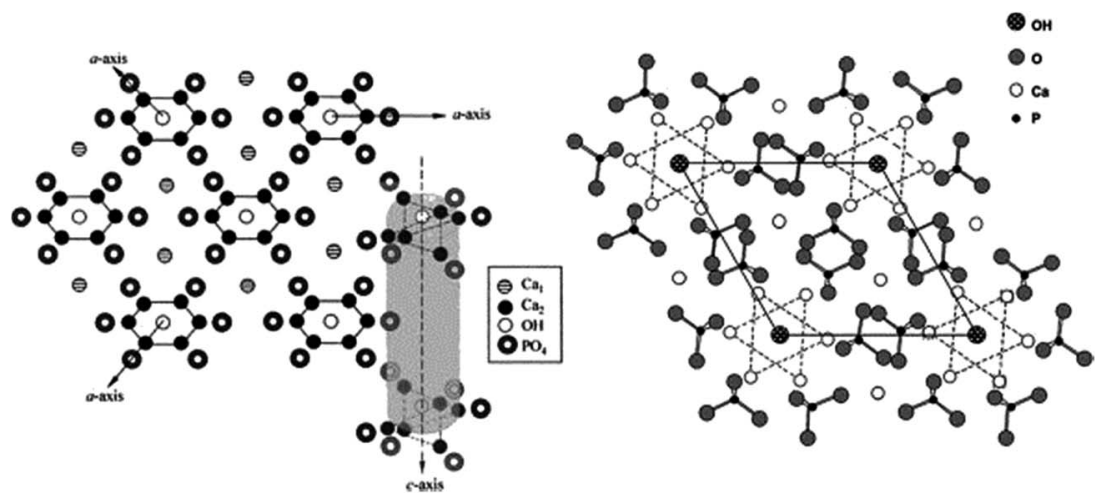

Fig. 3 Crystal structure of HA showing the c-axis perpendicular to 3 a-axes lying at $120^{\circ}$ of each other (left), and projection of the HA structure on the 001 plane (right) (this figure was reproduced with permission from John Wiley and Sons). ${ }^{4}$

precipitated and then calcined at $1000-1200{ }^{\circ} \mathrm{C}$ to refine the crystal structure. If the $\mathrm{Ca} / \mathrm{P}$ stoichiometry is not adjusted to 1.67 during the precipitation step, then other phases such as $\beta$-tricalcium phosphate (TCP) and $\mathrm{CaO}$ will be formed at lower and higher values, respectively. Furthermore, it is difficult to control the simultaneous nucleation, crystal growth, coarsening, and/or agglomeration, which occur during the precipitation of the HA particles. ${ }^{32}$ To synthesize HA particles with a tailored size, various additives such as allylamine hydrochloride, ${ }^{33}$ cetyltrimethyl ammonium bromide, ${ }^{34}$ and poly(acrylic acid) have been used. ${ }^{35}$

Kehoe et al. synthesized HA powders using a fractional factorial, resolution IV via a two-level experimental design to assess the critical process parameters (reagent addition rate, reaction temperature, stirring speed, ripening time, initial $\mathrm{Ca}$ concentration, and the presence of an inert atmosphere) and their effect (main and interaction) on the final HA powder characteristics, such as phase composition, purity, crystallinity, crystallite size, lattice parameters, particle size, and particle size distribution. This investigation of selected parameters showed an influence on one or more of the responses investigated, as either a main or an interaction effect. However, the ripening time and stirring speed significantly affected the majority of the five responses. In addition, the reaction temperature has a significant effect on the final phase composition, lattice parameters, and particle size as well. ${ }^{36}$ Low-temperature HT methods showed regulated ageing and a controlled size. ${ }^{37}$ Despite being a relatively simple technique for the synthesis of HA, SS methods have barely been reported (Fig. 4). The main limitations of this technique are the use of high temperature and longer reactions times, which allow the formation of different calcium phosphate phases $\left(\alpha\right.$ - and $\beta$-TCP $\left.\left(\mathrm{Ca}_{3}\left(\mathrm{PO}_{4}\right)_{2}\right)\right)$. The presence of these phases in the final product adversely affects the mechanical properties of HA, and thus, make its performance unpredictable. ${ }^{38}$ The SG technique is another common method to synthesize HA. This technique has advantages over the above-mentioned methods as it allows the use of low processing temperatures (lower than $400{ }^{\circ} \mathrm{C}$ ), results in a homogeneous molecular mixing, and generates nanosized particles. K. Agrawal et al. fabricated HA using the solution gel technique. They used phosphoric pentoxide $\left(\mathrm{P}_{2} \mathrm{O}_{5}\right)$ and calcium nitrate tetrahydrate $\left(\mathrm{Ca}\left(\mathrm{NO}_{3}\right)_{2} \cdot 4 \mathrm{H}_{2} \mathrm{O}\right)$ as precursors. After the mixing and gelation steps, they calcined the sample at 400 and $750{ }^{\circ} \mathrm{C}$ for $8 \mathrm{~h}$ to remove residues and enhance the crystallinity of the HA. They then characterized their final compound (HA) via various spectroscopic techniques. ${ }^{39}$ In general, to prepare uniform small-sized HA nanoparticles/nanorods, fast precipitation methods are preferred, which have the advantage of

Table 1 Synthetic techniques used for the synthesis of HA and characteristics of the resulting material

\begin{tabular}{|c|c|c|c|c|c|c|c|c|c|}
\hline Method & $\begin{array}{l}\text { Processing } \\
\text { time }(</>24 \mathrm{~h})\end{array}$ & $\begin{array}{l}\text { Temp } \\
\left({ }^{\circ} \mathrm{C}\right)\end{array}$ & Size $(\mu \mathrm{m})$ & $\begin{array}{l}\text { Degree of } \\
\text { crystallinity }\end{array}$ & $\begin{array}{l}\text { Phase } \\
\text { purity }\end{array}$ & Morphology & $\begin{array}{l}\text { Size } \\
\text { distribution }\end{array}$ & Cost & Ref. \\
\hline $\mathrm{CP}$ & $>$ & RT & $>0.1$ & Low & Variable & Diverse & Variable & Low & 37 and $41-44$ \\
\hline ESp & $>$ & - & $75 \times 40 \mathrm{~nm}$ & - & - & & - & Low & 19 \\
\hline ES & $>$ & - & $10 \times 10-30$ & - & - & Fibers & Variable & Variable & 18 \\
\hline MI & & - & $100 \times 25 \mathrm{~nm}$ & High & High & Diverse & Narrow & Variable & $22-24$ \\
\hline $\mathrm{FC}$ & $<$ & 500 & $18.0 \times 2.1$ & High & - & $\begin{array}{l}\text { Hexagonal } \\
\text { cylinders }\end{array}$ & - & Variable & 30 \\
\hline HT & $<$ & $150-400$ & $>0.05$ & High & High & Needle-like & Wide & High & 16 and 17 \\
\hline SS & $>$ & $1050-1250$ & $>2.0$ & High & Low & Diverse & Wide & Low & $14,15,20$ and 21 \\
\hline SG & $>$ & $37-85$ & $>0.001$ & Variable & Variable & Diverse & Narrow & Variable & 39 \\
\hline SPC & $<$ & $170-500$ & $>0.45$ & Variable & High & Diverse & Wide & Low & 25 \\
\hline EMe & $>$ & $\mathrm{RT}$ & $\begin{array}{l}>1.0 \text { (emulsion), } \\
>0.005 \text { (micro) }\end{array}$ & Low & Variable & Needle-like & Narrow & High & 26 \\
\hline
\end{tabular}




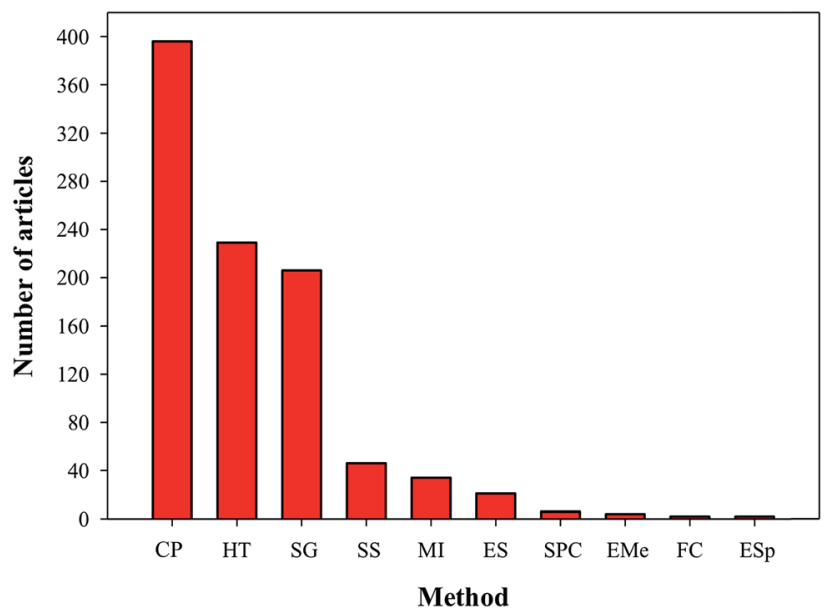

Fig. 4 Articles indexed in Scopus from 2007 to 2016 with the synthesis of HA using different techniques.

avoiding nucleation and crystal growth (which are the basis for attaining monodisperse particles). In addition to fast precipitation methods, aging techniques can also be used for the preparation of HA nanoparticles/nanorods. ${ }^{40}$ However, the synthesis of nanosized HA particles with the proper stoichiometry, high aspect ratio and good crystallinity are still difficult to obtain.

\subsection{Characterization techniques}

Various characterization techniques have been used to characterize HA in the form of nanoparticles, rods, discs, and powder. These characterization techniques are broadly classified as spectroscopic and direct visualization techniques. The details about the advantages and limitations of these techniques are given in Table 2. Fourier transform infrared (FTIR) and Raman spectroscopies, and X-ray techniques have been regularly used for the characterization of HA. Spectroscopic techniques such as FTIR and Raman are used to confirm the chemical composition of the HA. Both techniques use characteristics specific to the material to determine the composition. For example, HA shows various characteristic peaks in the FTIR spectrum at 3572 $\mathrm{cm}^{-1}$ (OH stretching), 1087, 1046, $1032 \mathrm{~cm}^{-1}$ (P-O stretching) and 631,602 , and $574 \mathrm{~cm}^{-1}$ (O-P-O bending) (Fig. 5I(a)). On the other hand, Raman spectra show characteristic HA peaks in the $1045-963 \mathrm{~cm}^{-1}$ region. The peak at $1045-1043 \mathrm{~cm}^{-1}$ is attributed to the asymmetric stretching of $\mathrm{P}-\mathrm{O}$, whereas the peak at $963 \mathrm{~cm}^{-1}$ confirms the presence of tetrahedral $\mathrm{PO}_{4}{ }^{3-}$ (Fig. 5I(b)). The presence of this peak at this position further confirms that HA is ordered and highly crystalline. ${ }^{45} \mathrm{X}$-ray photoelectron spectroscopy (XPS) is a surface-sensitive quantitative spectroscopic technique that provides elemental composition at parts per thousand range, and information about the empirical formula, chemical state, and electronic state of the elements within the material. In the XPS spectra, HA shows photoelectron signals (Fig. $5 \mathrm{I}(\mathrm{c}))$ at $347.9 \mathrm{eV}$ (Ca 2p), $536.1 \mathrm{eV}$ (O 1s), and $133.2 \mathrm{eV}$ (P 2p). These signals are commonly used to confirm the presence of HA. ${ }^{10}$ The X-ray diffraction (XRD) profile of HA usually shows characteristic diffraction peaks of nHA at 26.1, 28.45, 30.1, 32.90, 35.97, 40.19, 41.82, 53.56, 55.75, 57.40, $69.12,74.45$, and $77.56^{\circ}$, which correspond to the $002,102,210$, $112,300,212,130,213,321,004$, and 104 planes of the hexagonal HA unit cell (Fig. 5I(e)). ${ }^{46}$ Energy dispersive spectroscopy (EDS) is another very important technique used in combination

Table 2 Classification, advantages, and limitations of various techniques used to characterize HA nanoparticles and inorganic powder materials (these are normally analyzed by Raman spectroscopy rather than by FTIR)

Technique Advantages

Spectroscopic techniques

FTIR Measures the intensity over a narrow range of wavelengths at a time; no external calibration is required; provides accurate results, and identifies even small concentrations of contaminants

Raman Highly specific (provides a chemical fingerprint of the material); spectra inorganic materials are easier to analyze by Raman spectroscopy than by FTIR

XPS Provides unique information about the chemical composition of a material

XRD Powerful and rapid (<20 min) technique, provides an unambiguous mineral determination; data interpretation is relatively straightforward

EDS Chemical microanalysis technique used in conjunction with SEM; provides unique peaks characteristic of the atomic structure of the atoms; quick and versatile technique

\section{Direct visualization}

SEM Direct visualization, high resolution

TEM Direct visualization, high resolution

AFM High size resolution, 3D profile
Limitations

Inorganic materials are not easily analyzed by FTIR spectroscopy

The Raman effect is very weak. The detection requires a sensitive and highly optimized instrument; fluorescence of the impurities or of the sample itself can hide the Raman spectrum; sample heating by the intense laser radiation can destroy the sample or cover the Raman spectrum Slow, poor spatial resolution, requires high vacuum

Homogeneous and single phase materials are best for identification of an unknown; peak overlay may occur, and it is worse for high angle reflections Comparatively lower precision

NP aggregation during the sample preparation NP aggregation during the sample preparation, electron beam damage, preference for electron-dense atomic species Slow speed, limited scanning area 

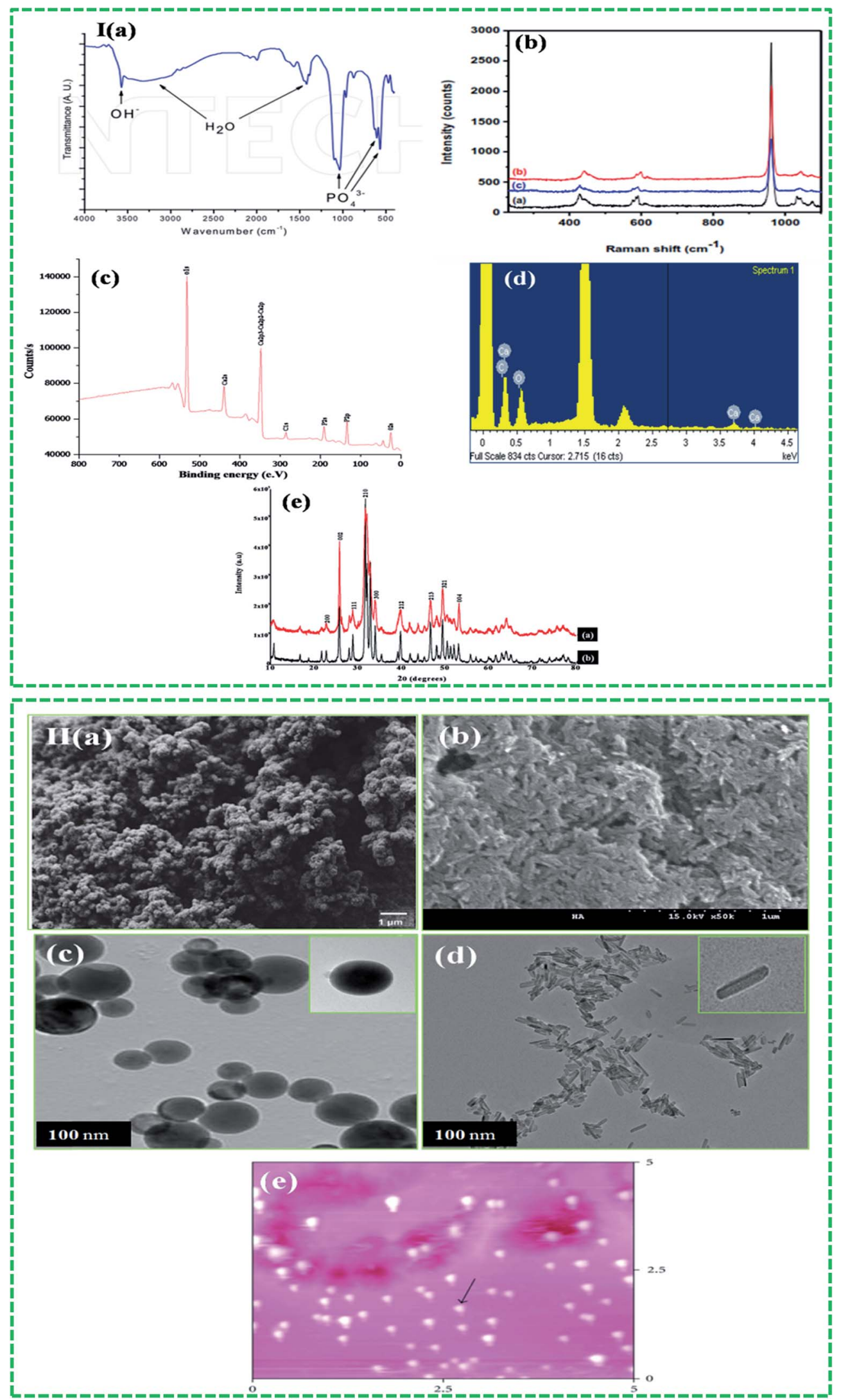

Fig. 5 Techniques used to characterize HA: I (a-e) spectroscopic (reproduced with permission from Springer and INTECH) ${ }^{10,45,48}$ and II ((a-e) ((b) is the unpublished figure owned by authors)) direct visualization (reproduced with permission from Hindawi). ${ }^{47,49}$ 
with scanning electron microscopy (SEM). In EDS technique, peaks appear due to the unique atomic structure of the atoms. For $\mathrm{HA}$, the unique peaks of $\mathrm{Ca}, \mathrm{P}$, and $\mathrm{O}$ appear at their characteristic positions, as shown in Fig. 5I(d). Direct visualization using SEM, transmission electron microscopy (TEM), and atomic force microscopy (AFM) provides information about the morphology, shape, size, and dispersion of the HA nanoparticles (Fig. 5II(a-e)). Occasionally, the information obtained from SEM is not very conclusive, and thus, supplementary techniques such as TEM and AFM are required to determine the dispersion, shape, and size of the HA nanoparticles. ${ }^{47}$

\section{Surface modification of $H A$ nanoparticles}

To control HA nanoparticle dispersion, delay the dissociation from the composite materials, and make them applicationspecific, researchers have studied several options. One of these options is surface modification. The aggregation of nanomaterials is a common issue encountered by researchers. Aggregation depends on the type of nanomaterials, surface energy, reagents or method used for nanoparticle synthesis and hydrophilic-hydrophobic interface between the solutions (polymeric or non-polymeric nanoparticles). To overcome this difficulty in HA nanoparticles, various emulsifying agents (like detergent or surfactant) and bridging agents (chemicals or coating the nanoparticles surface with some molecule) have been used. For example, Kim et al. used hydrostearic acid ${ }^{50}$ as a bridging agent between hydrophilic-hydrophobic HA and poly(L-lactic acid) (PLA). Bridging agents (mediators) are mainly amphiphilic compounds that contain both hydrophobic and hydrophilic moieties. Therefore, to achieve better HA dispersions in solution, the surface modification of HA via these bridging agents is promising not only for the fabrication of HA nanoparticles with uniform dispersions, but also for the preparation of composite scaffolds. In addition, another positive aspect of the surface modification is that it delays the dissociation of HA nanoparticles from the composite materials. Since HA nanoparticles are mostly used in biomedical applications, these bridging agents must fulfill certain requirements. Hence, they should not: (i) compromise the biocompatibility, (ii) be cytotoxic, and (iii) alter the physiological or biological properties of the nanoparticles or fillers. Different materials and methods have been used for the surface modification of HA (Table 3). For example, Tanaka et al. modified HA using decanoic and hexanoic acids, and these compounds bonded strongly to $\mathrm{P}-\mathrm{OH}$ via hydrogen bonding. These acids can be removed from the sample (restoring the original $\mathrm{P}-\mathrm{OH}$ surface) by outgassing the sample at $500{ }^{\circ} \mathrm{C}$. The use of carboxylic acids has two advantages: (i) using long chain acids (chain with more carbon atoms than acetic acid) would convert HA from hydrophilic to hydrophobic, and (ii) since animals contain different types of carboxylic acid moieties in the form of proteins, metabolic inhibitors, vitamins, and fats, HA interacts strongly with the carboxylic acids of these species. ${ }^{51}$ Tanaka et al. further improved their experiments and modified the surface of HA using pyrophosphoric acid (PP). PP reacted with the $\mathrm{P}-\mathrm{OH}$ surface of HA, resulting in the formation of additional $\mathrm{P}-\mathrm{OH}$ moieties along with phosphoric acids. ${ }^{52}$ Followed by Tanaka et al., Kim et al. used oleic acid (belongs to the fatty acids group, and it is amphiphilic and non-cytotoxic to human osteoblastic cells) to modify the surface of HA. ${ }^{53,54}$ Shimabayashi used the amphiphilic properties of the surfactant sodium dodecyl sulphate (SDS) to modify the surface of HA. ${ }^{56}$ They further immobilized bovine serum albumin and polyvinyl pyrrolidone (PVP) on the SDS-modified HA (HA-s); in the first case, SDS interacts electrostatically with the HA, while in the latter case, HA interacts hydrophobically with PVP. A similar but reverse mechanistic design was also reported by Haider et al. using carbon nanotubes and gelatin systems. ${ }^{55}$

Inorganic materials such as silanes are also suitable surface modifiers, as they stimulate adhesion, have a bonding ability, and can act as bridging agents for both inorganic and organic materials. Silanes anchored on HA will remain non-cytotoxic, compared to free silanes, which are considered cytotoxic. ${ }^{57,58}$ It is for this reason that silanes have been used in the fabrication of dental ${ }^{59}$ and bone implanting materials. ${ }^{60}$ Researchers have also used grafting (using polymers to improve dispersion and growth factors to enhance cell growth) to modify the surface of HA. For example, Hong et al. grafted L-lactide (LA) to HA using ring opening polymerization. ${ }^{61}$ The same authors also grafted poly(L-lactide) (PLLA) to HA via the carbonyl moieties of PLLA. They reported that the HA particles could be easily dispersed in PLLA using this method. ${ }^{62}$ Grafting techniques

Table 3 Different techniques used to modify the surface of HA

\begin{tabular}{|c|c|c|c|c|c|}
\hline Surface modifying agent & Technique & Ref. & Surface modifying agent & Technique & Ref. \\
\hline Hydrostearic acid & Direct reaction & 50 & PLLA & Grafting & 62 \\
\hline Decanoic and hexanoic acids & Direct reaction & 51 & BMP-2 & Grafting & 49 \\
\hline SDS & Direct reaction & 54 & Serum albumin and PVP & Grafting & 56 \\
\hline PP & Direct reaction & 52 and 64 & Vinylphosphonic acid & Grafting & 65 \\
\hline Silanes & Coating & 58 & Ethylene glycol methacrylate phosphate & Polymerization & 66 \\
\hline Polyacrylic acid & Coating & 68 & $\gamma$-Benzyl-L-glutamate $N$-carboxyanhydride & Polymerization & 69 \\
\hline$\gamma$-Methacroyloxytrimethylsilane & Coating & 70 & L-Phenylalanine $N$-carboxyanhydride & Polymerization & 71 \\
\hline
\end{tabular}




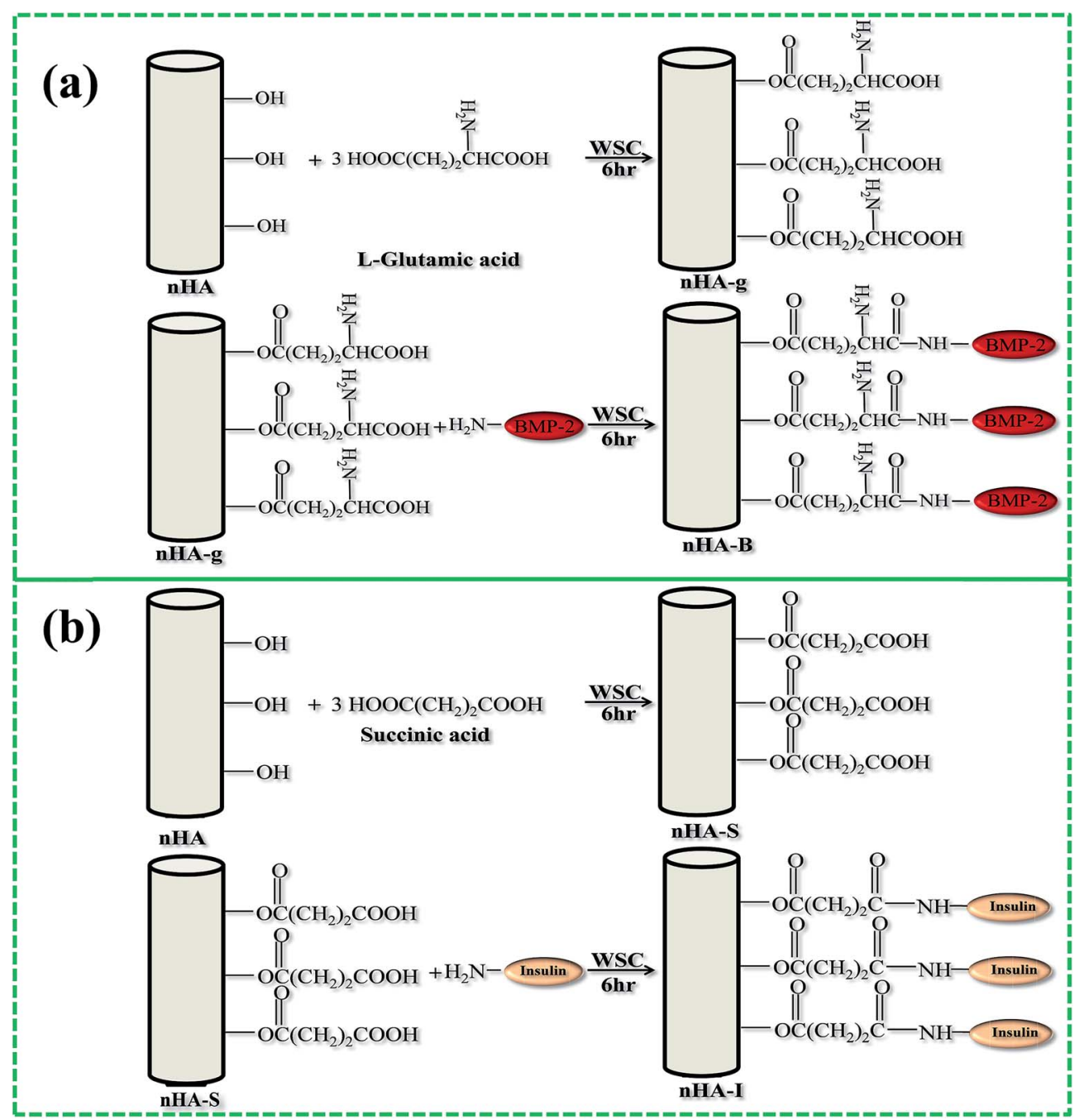

Fig. 6 Schematic representation of the grafting of (a) BMP-2, and (b) insulin on the surface of nHA (reproduced with permission from Springer and Hindawi). ${ }^{10,63}$

have been used recently by Haider et al. as well to immobilize growth factors such as bone morphogenetic protein (BMP-2) and insulin on HA(Fig. 6(a) and (b)). They have not only observed good dispersion HA, but also an enhanced cell proliferation on the HA-based scaffolds. The figure was reproduced with permission from Springer. ${ }^{10,49}$

\section{Ion-doping of HA nanoparticles}

Doping of HA with foreign ions is another method that has been focused by researchers in recent years. Even though doping of foreign ions into HA has been document in literature, however, not many studies were focused on cell cultural or these were only focused on one type of doping ion. This lack of research on the doping of foreign ions into HA for use in cellular cultural made it difficult for researchers to evaluate the effect of doping ions on the HA interaction with cell. Recently various ions such as strontium $\left(\mathrm{Sr}^{2+}\right)$, magnesium $\left(\mathrm{Mg}^{2+}\right)$, iron $\left(\mathrm{Fe}^{3+}\right)$, manganese $\left(\mathrm{Mn}^{2+}\right)$, zinc $\left(\mathrm{Zn}^{2+}\right)$, carbonate $\left(\mathrm{CO}_{3}{ }^{2-}\right)$, silicate $\left(\mathrm{SiO}_{4}{ }^{4-}\right)$, etc., have been doped into the structure of HA. The presence of these dopants in the structure of HA are significant for the biostructure and biochemistry of the HA to be similar to natural bone. ${ }^{72,73}$ The doping of these ions into HA did not disturb the structure configuration, as HA is known for accommodating different ions: however, in some cases the crystallinity, morphology and solubility of HA were changed. Studies have shown that these changes did not affect cell behaviour, though in some cases cellular biocompatibility properties were changed. This issue was well highlighted by Zhao et al. who have shown that the selection of doping ions has a strong impact on cell behaviour e.g. a minute amount of $\mathrm{Mg}^{2+}$ ions in the HA ( 1.5 wt\%) could lead to a significant cytotoxicity in MG63 cells, but not in rMSCs. They further elaborated that HA internalization (endocytosis) is affected by the stabilization of negative surface charge. This effect was more pronounced in MG63 as compared to rMSCs. Research with $\mathrm{Mg}^{2+}$ doped HA further suggested that these nanoparticles could be used to kill cancer cells. This use of such particles will not only eliminate the need of conjugating anticancer drugs onto the nanoparticles but will also solve the issue associated with drug 
toxicity. ${ }^{74}$ Thus a proper selection of the foreign doping ions is imperative, if $\mathrm{HA}$ is intended for use in cell culture. In another study Subhadip et al. studied the effect of $\mathrm{Sr}^{2+}$ and $\mathrm{Mg}^{2+}$ dopants on the structural stability and biological properties of HA. They observed that the presence of $\mathrm{Mg}^{2+}$ and $\mathrm{Sr}^{2+}$ not only enhanced the stability of the particles but also improved the osteoblast response activities and density of the viable cell on a negatively charged surface for all cultural periods. Thus, they have concluded that metal ion dopants affect mineral metabolism in the bone remodelling process and enhance the osteoclast apoptosis as well as preosteoblastic cell proliferation. The presence of these dopants in the HA could lead to the designing of bone graft materials that could be of potential use in tissue regeneration for faster healing. ${ }^{75} \mathrm{Li}$ et al. doped $\mathrm{HA}$ with manganese $\left(\mathrm{Mn}^{2+}\right)$ and iron $\left(\mathrm{Fe}^{3+}\right)$ ions using wet chemical method and ions exchange mechanism. The samples showed no deviation from the structure, morphology and crystal size, and were single phased and B-type carbonated HA (carbonate groups partially replaced phosphate groups in the lattice structure). Both dopants showed no toxic effect on osteoblast cells. $\mathrm{Fe}^{3+}$ doped HA illustrated enhanced osteoblast cell adhesion and increased negative surface charge as compared to $\mathrm{Mn}^{2+} \mathrm{HA}$ and pristine HA. ${ }^{76}$ The evidences in the above mentioned studies is clearly showing that metal cations dopants can extract more physicomechanical and biological benefits, when incorporated into at issue-engineering construct. Most of the cations dopants are non-harmful even at considerable high concentration. Having said this and as described above some cations can cause toxicity if their concentration is increased beyond a certain level. Furthermore, appropriate considerations must be given to the type of a chemical compound that intended for use in metal doping of the biomaterials. This precaution is imperative because some chemical entities might cause toxicity in the host tissue, although the cations used their selves are not toxic. Besides, very little information is on hand regarding the bioavailability of the metal dopants when released from biomaterials in vivo during biodegradation. In addition, the mechanism of action of dopants at the cellular level has not well reported in the literature. Despite all these limitations and drawbacks, the existing research has provided exciting evidences, which suggests that further work with metal doped bioceramics is not only going to be well-timed but also worthy of fast healing the tissue implant. ${ }^{77}$

\section{Applications of HA nanoparticles}

The interaction between inorganic materials and protein molecules is of pivotal interest for researchers working in the field of biomaterials, biomineralization, biosensors, biochemistry, and industry. ${ }^{77}$ Scientists working in the field of drug delivery and tissue regeneration, more specifically in bone tissue regeneration, have acquired sufficient knowledge to determine the interaction between $\mathrm{HA}$ and various proteins. HA crystals have two binding sites, i.e. " $\mathrm{C}$ " sites $\left(\mathrm{Ca}^{2+}\right)$ and " $\mathrm{P}$ " sites $\left(\mathrm{PO}_{4}{ }^{-}\right)$owing to its chemical composition and specific orientation. Within a crystal, the "C" sites are arranged in a rectangular manner, whereas " $C$ " sites are arranged along the $c$-axis surfaces in the hexagonal configuration (Fig. 7). ${ }^{79-81} \mathrm{By}$ suspending $\mathrm{HA}$ in aqueous media, the " $\mathrm{C}$ " sites are exposed and they acquire positive charge, which is mainly attributed to the release of $\mathrm{OH}^{-}$ions from the crystal surface. The "C" sites, after the release of the $\mathrm{OH}^{-}$ions, are left with positively charged $\mathrm{Ca}^{2+}$ ions. These positively charged $\mathrm{Ca}^{2+}$ ions interact with the negatively charged proteins. Chen et al. reported that $-\mathrm{COO}^{-}$ ions with their negatively charged oxygen interact with the " $\mathrm{C}$ " sites of HA. ${ }^{82}$ Shaw et al. also confirmed via solid state NMR that terminal $-\mathrm{COO}^{-}$amelogenin ions interact with the HA surface. ${ }^{83}$ On the other hand, "P" sites are negatively charged ions $\left(\mathrm{P}\left(\mathrm{PO}_{4}^{-}\right)\right)$, which interact with the positively charged proteins. In addition to their reactivity with proteins, HA is also used under physiological conditions. Therefore, HA has also been used in chromatography for separating various proteins. $^{\mathbf{8 4 , 8 5}}$ Since HA, due to its biocompatible properties, has a higher potential for applications in the biomedical field, scientists working in the orthopedic field have been using HA on the bone implanting material. Besides its use as an implanting material, HA has been used in gene delivery, cancer therapy and as a bio imaging tool. Gene therapy is a long recognised promise for the treatment of a wide range of incurable diseases through replacement of the missing or defective genes, catalyzing the destruction of cancer cells, causing the cancer cells to revert back to normal tissue, promoting the growth of new tissue or stimulating regeneration of the damaged tissue. ${ }^{\mathbf{8 6 , 8 7}}$ However, this promise still remains unfulfilled, primarily due to the lack of a safe and competent vehicle for the delivery of gene. HA is considered a potential candidate for this purpose as HA possess characteristics of an ideal gene vehicle. The potential of the HA as gene delivery vehicle was evaluated by Tan et al., who compared the non-viral gene delivery of neutrally charged HA and positively charged zirconia $\left(\mathrm{ZrO}_{2}\right)$. In their work they found that a mixture of highly monodispersed aqueous suspension of HA nanoparticles, coated with protamine sulfate (PS), complexed efficiently with plasmid DNA and significantly

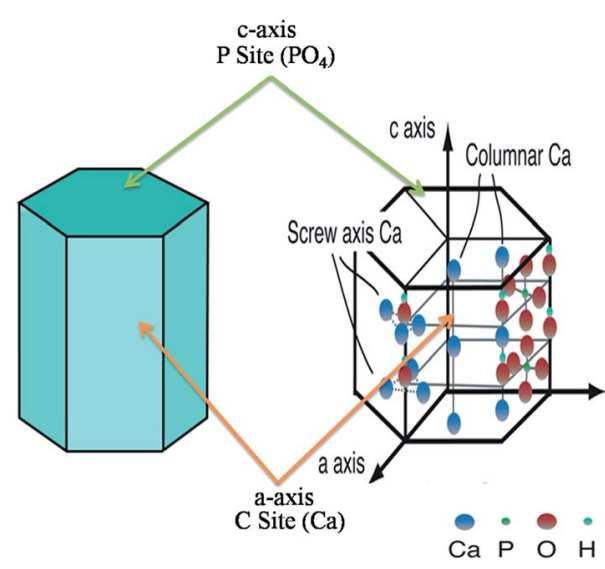

Fig. 7 Hexagonal crystal structure of $\mathrm{HA}$ with " $\mathrm{C}$ " and "P" sites. The figure was redrawn by the authors from the work of Uddin et al. and Okada and T. Matsumoto (reproduced with permission from INTECH). ${ }^{90,91}$ 
enhanced trans gene expression in vitro as compared to $\mathrm{ZrO}_{2}{ }^{86}$ Similarly, Liu et al. proposed that HA-based nanoparticles could be used for bioimaging of living cells as well. For example, the authors prepared well dispersed fluorescein isothiocyanatelabeled $\mathrm{HA}$ nanoparticles using $\mathrm{SiO}_{2}$ as template for imaging tissues or intracellular structures. ${ }^{88}$ Thus with fluorescence imaging method using nontoxic fluorescent hydroxyapatite (fHA) nanomaterials, visualization of the complete organ in complicated biological processes is possible. ${ }^{89}$ A detailed description of some of the most important applications is given below.

\subsection{HA as a drug delivery carrier}

Most biological $\mathrm{Ca}$ apatites are known for their irregular morphologies, which result from the presence of residue materials in the apatites. However, the surface of HA is rough, which favours the use of HA in biomedical applications. The rough surface together with the "P" and "C" sites of HA facilitates protein binding during the process of mineralization. ${ }^{92}$ The importance of the rough surface and the "P" and "C" sites has been confirmed by the interaction of amino acids with HA. ${ }^{92}$ During the last decade, research has been focused on the use of HA as a drug delivery carrier, and this is evident from the increasing number of research articles each year (Fig. 8) (this data was obtained from Scopus). Several researchers are investigating the use of HA nanorods/nanoparticles as a drug delivery carrier for various proteins (growth factors) and drugs. ${ }^{10,49,93}$ For example, Haider et al. modified the surface of HA with a spacer using an amino acid (glutamic acid). They immobilized proteins growth factors (protein drug) on the free terminal groups (carboxylic $(-\mathrm{COOH})$ or amine $\left(-\mathrm{NH}_{2}\right)$ moieties) of the spacer. The drug-loaded/modified HA nanorods/nanoparticles were then blended with a polymeric solution to carry the drug-loaded HA to the target site. ${ }^{61}$ Yewle $e$ et al. oriented proteins on the surface of HA using bifunctional hydrazine bisphosphonate (HBP) with hydrazone bonds (Fig. 9(a)). They first modified the surface of HA with HBP, followed by the immobilization

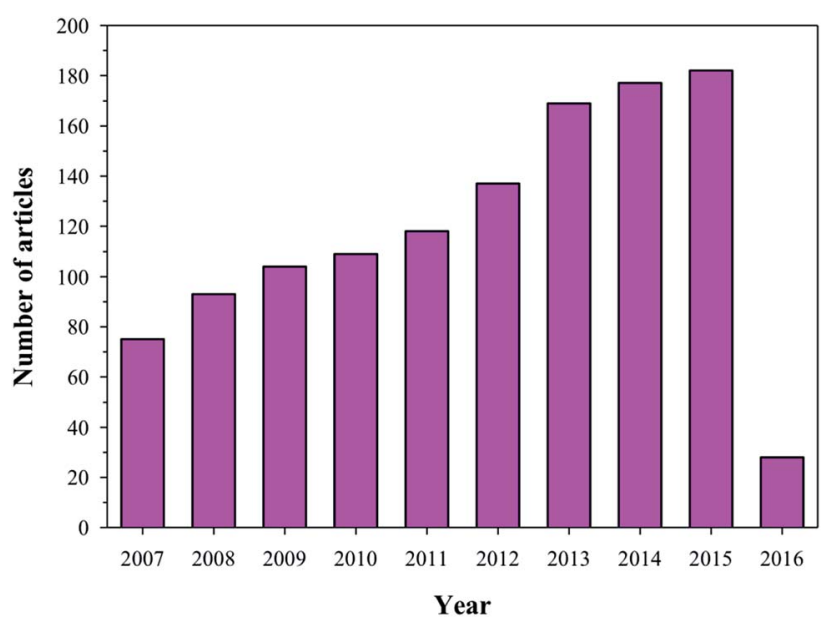

Fig. 8 Articles indexed in Scopus from 2007 to 2016 with the application of $\mathrm{HA}$ in drug delivery systems. of the protein with aldehyde functionality. The aldehyde functionality was obtained via oxidation of the N-terminal of serine and threonine. From the analysis of the results, they concluded that the oriented proteins showed better activity as compared to the absorbed proteins. ${ }^{94}$ Furthermore, Li et al. fabricated Gddoped luminescent HA and mesoporous SrHA nanorods and reported that their HA-modified aptamers could be used as a therapeutic agent against cancerous cells (Fig. 9(c)). ${ }^{95}$ Son et al. used HA coated with Ti discs (Fig. 9(b)) for the delivery of bioactive drug molecules (dexamethasone (DEX)) using biodegradable poly(lactide-co-glycolide) (PLGA) nanoparticles. In their study, they coated the surface of Ti with HA and electrostatically immobilized DEX-loaded PLGA nanoparticles on the coated surface. ${ }^{96}$ The sample with the lowest surface roughness $\mathrm{S}_{3}$ (as shown in Fig. 9(b)) showed not only a sustained release of DEX over a period of 30 days, but also developed more extracellular matrix on it. Recently, Ibrahim et al. used a very simple methodology and produced mesoporous HA nanopowder with a pore volume of $1.4 \mathrm{~cm}^{3} \mathrm{~g}^{-1}$ and a surface area and of $284.1 \mathrm{~m}^{2}$ $\mathrm{g}^{-1}$ from raw eggshells at room temperature using a simple twostep procedure. The as-prepared HA nanopowder showed high loading of ibuprofen drug (1.38 $\left.\mathrm{g} \mathrm{g}^{-1} \mathrm{HA}\right)$, which was used as model drug. Good dissolution and controlled release of the drug via solute-saturated supercritical $\mathrm{CO}_{2}$ was observed (Fig. 9(d)). ${ }^{97}$ Besides these studies, various research groups around the world are working on the sustainable use of HA as a drug delivery carrier on the surface of implanting materials (in one way or the other) to improve the bioactivity of the implanting material..$^{98-101}$

\subsection{HA as a coating material}

To restore a damaged bone, it is imperative to design a bone implanting material that can be used not only for curing the bone defect, but also for reconstructing the bone. There are several difficulties in fabricating suitable bone implanting materials. For example, the first difficulty that commonly appears is the synchronization between the implanting material and bone during the bone remodelling process (resorption and reparative process). The implanting material should not have any adverse effects on the immune system. To date, the methods used for managing bone defects are allografting, autografting, and synthetic (fabricated using HA or naturally occurring biocompatible substances) bone implantation techniques. However, all these techniques have their limitations. For example, the implanting materials sometimes resorb before the osteogenesis, rendering the material ineffective. ${ }^{103,104}$ In other cases, infections due to the implants result in incidence of disease and even death, which are very costly to the patient in particular and society in general..$^{105}$ Owing to these reasons, it is necessary to devise a way to design and fabricate suitable bone tissue regenerating implants. For the fabrication of an implanting material, four vital aspects of an implant should be considered: (i) the implanting material should have a signal carrier, (ii) the implanting material should present a morphogenetic signal, (iii) responsive cells for the signals should be present in the implanting sites, and (iv) the existence of a well 
(a)

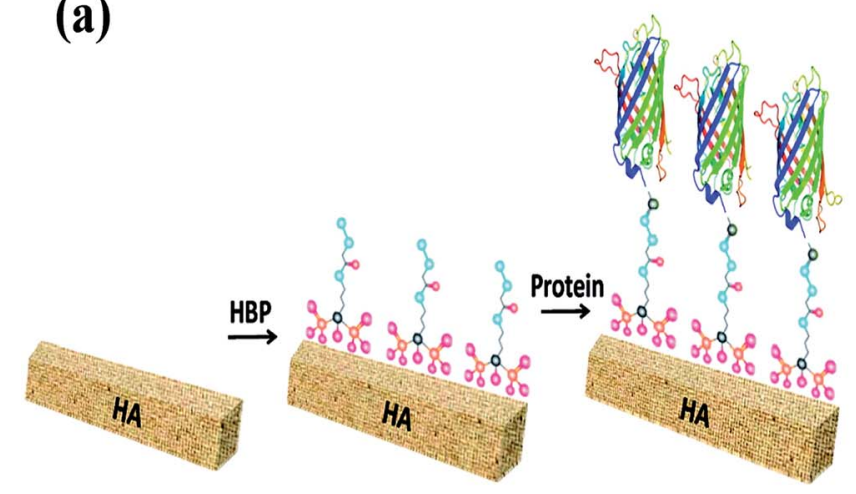

(b)

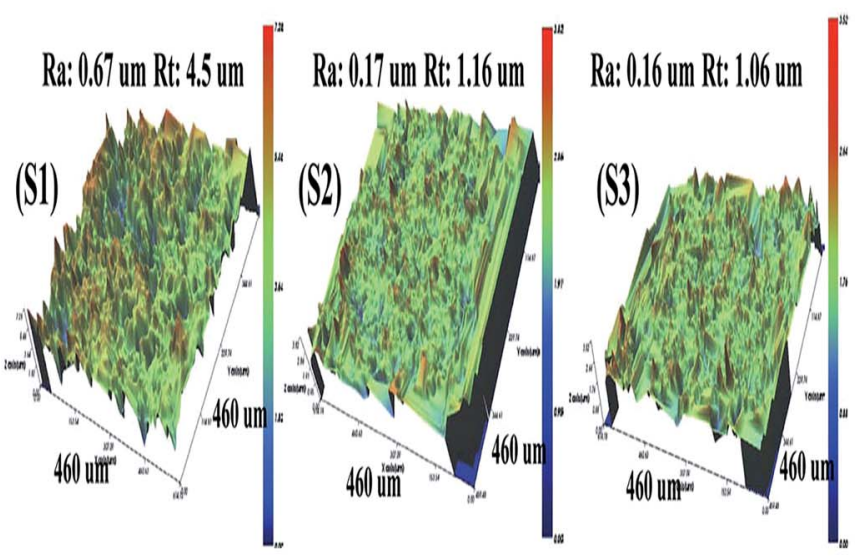

(c)

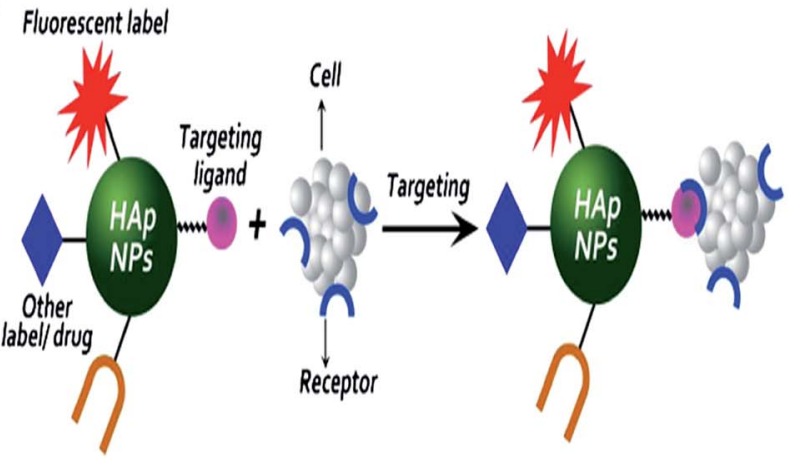

Magneticlabel (d)

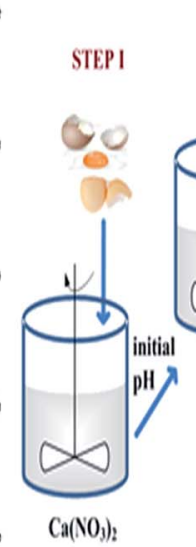

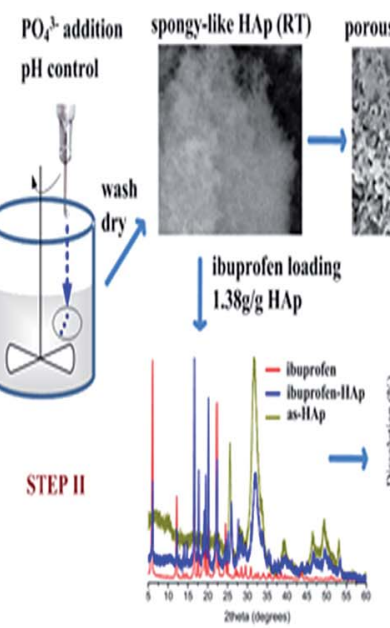

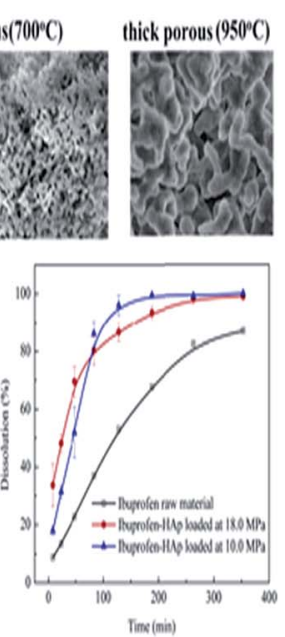

Fig. 9 (a) Schematic for the oriented proteins on the surface of HA using bifunctional HBP and immobilization of proteins (reproduced with permission from ACS), ${ }^{94}$ (b) three-dimensional (3D) interactive display images obtained by optical profiling of the Ti disc surfaces. $R_{\mathrm{a}}$ : roughness average, $R_{\mathrm{t}}$ : roughness height. (S1) Resorbable blast media (RBM) on a Ti disc, (S2) RBM on a HA-Ti disc, and (S3) DEX-loaded PLGA particles immobilized on a HA-Ti disc (reproduced with permission from John Wiley Sons), ${ }^{96}$ (c) schematic representation of HA-based nanoprobe targeting bioimaging and drug delivery (reproduced with permission from Springer), ${ }^{102}$ and (d) illustration of the methodology, morphology, and drug release profiles of the spongy-like mesoporous HA prepared using raw waste eggshells. ${ }^{97}$

vascularised host bed. ${ }^{106}$ Recently, a technique has been used where an implant is coated with a biocompatible and bioactive material to enhance the compatibility and bioactivity of the implanting material. For bone tissue regeneration and implanting, the most common coating agent used is HA. The importance of HA as a coating material is evident from the number of articles that have been published in the last decade using HA as coating material (Fig. 10). HA has been used as a coating material because it chemically resembles natural bone. Furthermore, coating of the implanting material surfaces (usually metallic prosthesis) with HA enhances the osteointegration with bone. ${ }^{107}$ Sintered HA can adhere tightly to the bone, thus hindering degradation. J. He et al. used a thin coating of HA on a Ti implanting surface via a plasma spraying method. ${ }^{109}$ The advantage of this method is that it avoided a sub-optimal fatigue of the sintered HA. Other well-known methods that have been used to coat HA on the surface of implanting materials (metallic) sputter coating, include dip coating, pulsed laser deposition, hot pressing and hot isostatic pressing, thermal spraying, electrostatic spraying, electrophoretic deposition,

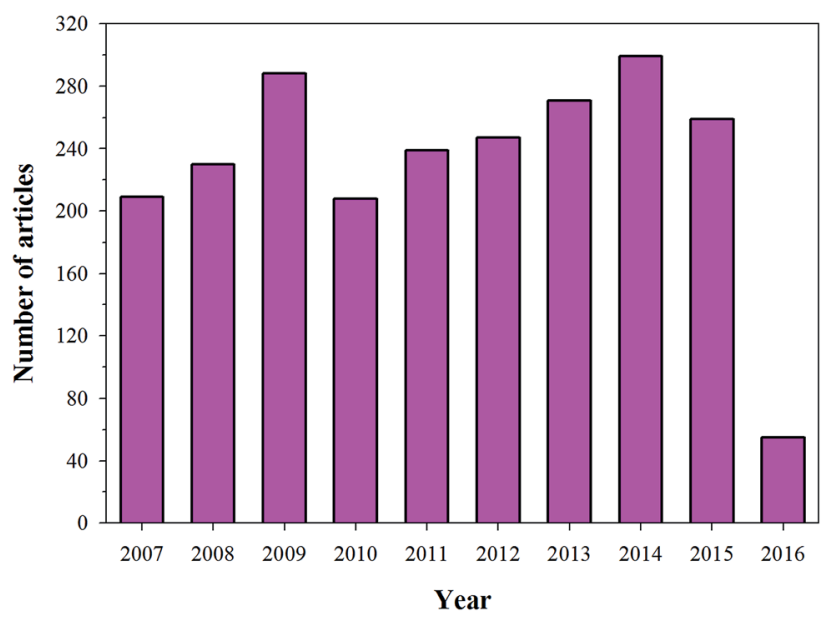

Fig. 10 Articles indexed in Scopus from 2007 to 2016 using HA as a coating material. 
solution gel, pulse laser deposition, and an electrostatic layerby-layer sputtering method. ${ }^{\mathbf{1 0 5 , 1 0 9}}$ The advantages and disadvantages of these coating techniques are presented in Table 4. Researchers working in the field of bone tissue regeneration have concluded that the shear strength of a Ti alloy coated with $\mathrm{HA}$ is similar to that of cortical bone. ${ }^{\mathbf{1 1 0}}$ Rigo et al. coated a silicon nitride surface with HA to enhance its bioactivity and biocompatibility. Silicon nitride has good mechanical strength, but it has limited biomedical applications due to its inertness. ${ }^{111}$ LeGeros concluded that osteoblastic cells could easily interact with the HA-coated surface. ${ }^{112}$ These interactions will lead to the formation of osteoids and thus to chemical and biological interactions between the implanting material and bone in a safe manner. The authors also concluded that besides the osteoconductive properties, HA (with a 3D morphology) also shows osteoinductive properties when it binds and interacts with bone morphogenetic proteins (BMPs). ${ }^{\mathbf{1 1 2}}$ All the techniques used for coating HA on the surface of metal alloy prosthesis and other orthopedic implanting materials helped in stimulating new bone growth under optimized conditions. ${ }^{105}$ However, limitations associated with the necessity and effectiveness of
HA coatings for various anatomic sites, the strength of HA coatings to withstand physiological loads without fragmentation, and the issues related to third-body wear by HA particles restrict its applicability. ${ }^{\mathbf{1 0 5}}$

\subsection{HA-based composite materials}

As mentioned earlier, polymers are of great use in the field of tissue regeneration. The polymers used in bone regeneration can be either biodegradable or non-degradable and can have a natural or synthetic origin. In the latter half of the $19^{\text {th }}$ century, Urist et al. concluded that polymers induced bone formation in animals. ${ }^{\mathbf{1 1 3 - 1 1 5}}$ Similarly, Kulkarni et al. concluded that the morphology of polymer-based implants and the implanting sites were pivotal in stimulating bone tissue regeneration. They reported that tubular absorbable polymer implants could enhance bone tissue regeneration in long bones. ${ }^{116}$ Various synthetic polymers have been tested directly or in combination with HA to mimic natural bone matrix. Among them, PLGA, ${ }^{117}$ PLA, ${ }^{\mathbf{1 1 8 , 1 1 9}}$ and poly(caprolactone) ${ }^{\mathbf{1 2 0 , 1 2 1}}$ are the most frequently used polyesters. In most polymeric composites, HA has been used as an enforcer to provide

Table 4 HA coating techniques and their characteristics (reproduced with permission from INTECH) ${ }^{108}$

\begin{tabular}{|c|c|c|c|}
\hline Techniques & Advantage & Disadvantage & Thickness \\
\hline \multirow[t]{3}{*}{ Dip coating } & Inexpensive & High sintering temperatures & \multirow[t]{3}{*}{$0.05-2 \mathrm{~mm}$} \\
\hline & Coatings applied quickly & $\begin{array}{l}\text { Thermal expansion results in } \\
\text { an amorphous coating }\end{array}$ & \\
\hline & Coats 3D complex porous substrates & Fragile due to the thickness & \\
\hline \multirow[t]{5}{*}{ Sputter coating } & Uniform coating thickness & Only coats visible areas & \multirow[t]{5}{*}{$0.02-2 \mu \mathrm{m}$} \\
\hline & on flat substrates & Expensive and time-consuming & \\
\hline & & Unable to coat complex 3D & \\
\hline & & porous substrates & \\
\hline & & Risk of amorphous coatings & \\
\hline \multirow[t]{3}{*}{ Pulsed laser deposition } & Uniform coating thickness & Only coats visible areas & \multirow[t]{3}{*}{$1-10 \mu \mathrm{m}$} \\
\hline & on flat substrates & Expensive and time-consuming & \\
\hline & & Unable to coat complex 3D substrates & \\
\hline \multirow{3}{*}{$\begin{array}{l}\text { Electrostatic spray } \\
\text { deposition }\end{array}$} & Uniform coating thickness & Only coats visible areas & \multirow[t]{3}{*}{$1-10 \mu \mathrm{m}$} \\
\hline & on flat Substrates & & \\
\hline & Relatively cheap & Fragile & \\
\hline \multirow{3}{*}{$\begin{array}{l}\text { Electrophoretic } \\
\text { deposition }\end{array}$} & Uniform coating thickness & Cracks during coating & \multirow[t]{3}{*}{$0.1-200 \mu \mathrm{m}$} \\
\hline & High deposition rates & High sintering temperatures & \\
\hline & Coats complex 3D porous substrates & & \\
\hline \multirow{2}{*}{$\begin{array}{l}\text { Electrostatic spraying, } \\
\text { plasma spraying }\end{array}$} & High deposition rates & Only coats visible areas & \multirow[t]{2}{*}{$30-200 \mu \mathrm{m}$} \\
\hline & & $\begin{array}{l}\text { Coating decomposition due to high temperature } \\
\text { Rapid cooling may result in amorphous coatings }\end{array}$ & \\
\hline \multirow[t]{3}{*}{ SG } & Coats 3D complex porous substrates & Processing in controlled atmosphere & \multirow[t]{3}{*}{$<1 \mu \mathrm{m}$} \\
\hline & Low processing temperatures & & \\
\hline & $\begin{array}{l}\text { Relatively cheap and forms } \\
\text { very thin coatings }\end{array}$ & & \\
\hline \multirow{4}{*}{$\begin{array}{l}\text { Hot pressing, hot isostatic } \\
\text { pressing and sintering }\end{array}$} & Dense coatings & Unable to coat complex $3 \mathrm{D}$ porous substrates & \multirow[t]{4}{*}{$0.1-10 \mathrm{~mm}$} \\
\hline & & Differences in coating elasticity & \\
\hline & & Expensive & \\
\hline & & $\begin{array}{l}\text { Interaction with or changes due to the } \\
\text { encapsulation of the material }\end{array}$ & \\
\hline \multirow[t]{5}{*}{ Layer-by-layer coatings } & Controlled loading efficiency and release & Require the use of a few hundred layers & \multirow[t]{5}{*}{$0.1-0.61 \mu \mathrm{m}$} \\
\hline & kinetics of the encapsulated & to avoid a burst release of biomolecule & \\
\hline & biomolecules, various & Requires an acidic solution for an & \\
\hline & & effective loading & \\
\hline & & Low mechanical stability & \\
\hline
\end{tabular}


mechanical strength and bioactivity to the composite material. ${ }^{10,49,93}$ The importance of HA in bone tissue regeneration has been reported extensively. Even though research on the application of HA composites is advancing slowly, it has been steadily increasing. This is evident from the number of articles published on this topic over the last decade (Fig. 11). Various researchers have fabricated $\mathrm{HA} /$ polymer scaffolds for use as a drug delivery carrier, improved bone tissue regeneration (grafting proteins and drugs on the surface of HA) and treatment of various bone defects such as osteoporosis. Haider et al. immobilized insulin and BMP-2 on the surface of HA. The modified HA was incorporated in PLGA to prepare HA/PLGA composites. They concluded that after the protein was immobilized on HA and its composting with PLGA, the composite enhanced osteoblastic cell growth and accelerated osteogenesis. $^{49}$ In another study, the authors also immobilized pamidronic acid on the surface of HA to treat osteoporosis. Due to excessive osteoclastic activity, bones are prone to break; hence, they concluded from their experiments that pamidronic acid reduced the osteoclastic cell activity. They also showed that the presence of HA enhanced the osteoblastic cell activity. ${ }^{122}$ Ignjatovic et al. fabricated a HA/PLLA composite, whereas Wang et al. synthesized a HA/polyethylene composite. They concluded that these composites have sufficient mechanical strength to be used in bone regeneration. ${ }^{123,124}$ Bakos fabricated a HA/collagen composite by blending to mimic natural bone. The composite showed bend strength of $5.37 \mathrm{kPa}$, and they concluded that this material could find applications in cases where better cohesion and shape stability are required. ${ }^{123,125-127}$ Dalby et al. prepared a HA/poly(methylmethacrylate) (PMMA) composite and revealed that this material acts as a substrate for human osteoblast-like cells. ${ }^{\mathbf{1 2 3 , 1 2 5 - 1 2 7}}$ In another study, a group of researchers tried a variety of combinations of chitosan and HA to improve the biocompatibility and mechanical strength of chitosan-based materials. For example, a composite containing high molecular weight chitosan and HA particles was prepared

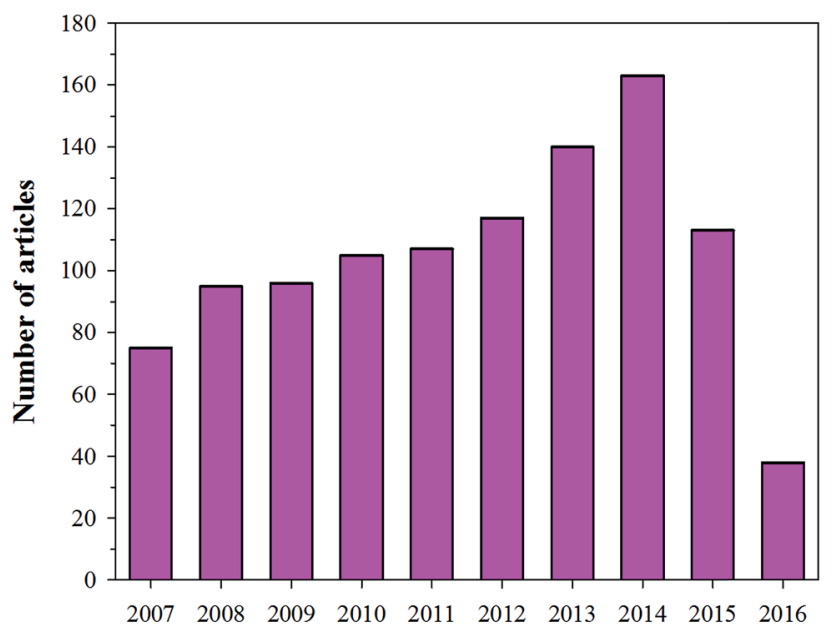

Year

Fig. 11 Articles indexed in Scopus from 2007 to 2016 with HA-based composite materials. by freezing and lyophilisation. The composite showed better mechanical properties than medium molecular weight chitosan ones. ${ }^{128}$ Furthermore, various collagen compositions with HA have been reported as well, which have shown better biocompatibility and enzymatic degradability. ${ }^{\mathbf{1 2 9 - 1 3 2}}$

\subsection{HA-based ceramics in bone tissue regeneration}

Natural bone is a ceramic composite comprised of calcium phosphate, collagen, and water. Apart from these major constituents, polysaccharides, lipids, and proteins are also found in natural bone in small amounts. Calcium phosphate is present in bones in the form of HA crystals, which provides rigidity to the bone. The HA components are similar to those of bone with some impurities of $\mathrm{Na}^{+}, \mathrm{Mg}^{2+}$, and $\mathrm{F}^{-}$ions. $\mathrm{HA}$ crystals in bone are in the nanometer range for length and width. The presence of HA in an implant not only enhances the osteoinductive behaviour of the implant, but it also improves the osteoconductive properties between the implant and the bone cells (osteoblastic cells). ${ }^{\mathbf{1 2 5}}$ Owing to the similarity between HA and inorganic cement of natural bone, HA has been frequently used either in pristine, composite, or ceramic form for bone tissue regeneration. This is evident from the number of articles published on this topic between 2007 and 2016 (Fig. 12). To achieve the desired goal (safe and satisfactory bone regeneration), the selected materials for an implant should have similar properties to those of natural bone. The knowledge of the natural environment of bone osteoblastic cells is imperative, if infection-free bone regeneration is desired. Several HA bioceramics have been prepared to mimic natural bone. However, as mentioned above, it is necessary that the implants provide an environment close to the natural one. For example, besides other factors, the implant must have a mechanical strength close to that of the bone. Hence, the difference in mechanical strength between the implant and bone should not exceed a factor of 55 (between moduli) with respect to cortical bone, or it will have an adverse effect on the living cells of the bone (due to the bone shielding by the bioceramic implanting

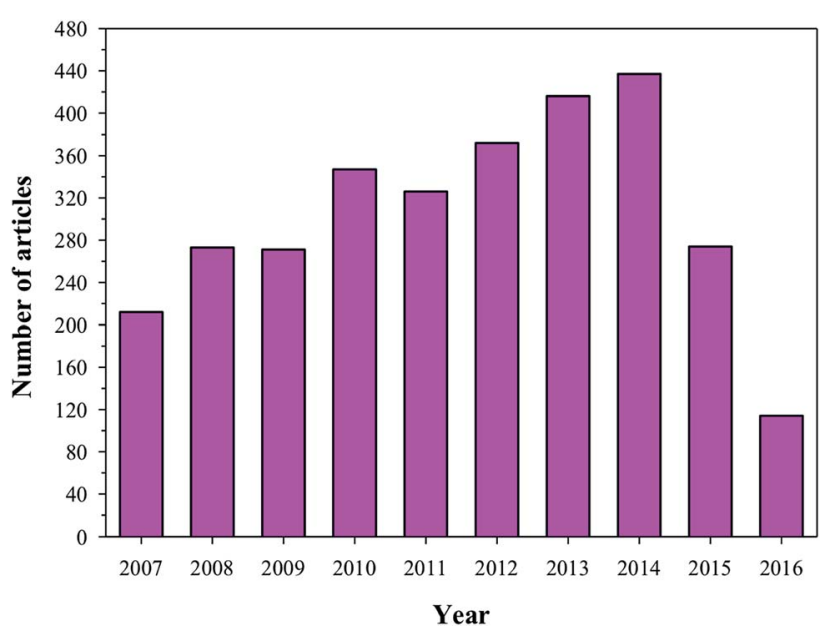

Fig. 12 Articles indexed in Scopus from 2007 to 2016 with the application of HA in tissue engineering. 
Table 5 Synthesis methods and various characteristics of HA bio-ceramics (reproduced with permission from MDPI) ${ }^{145}$

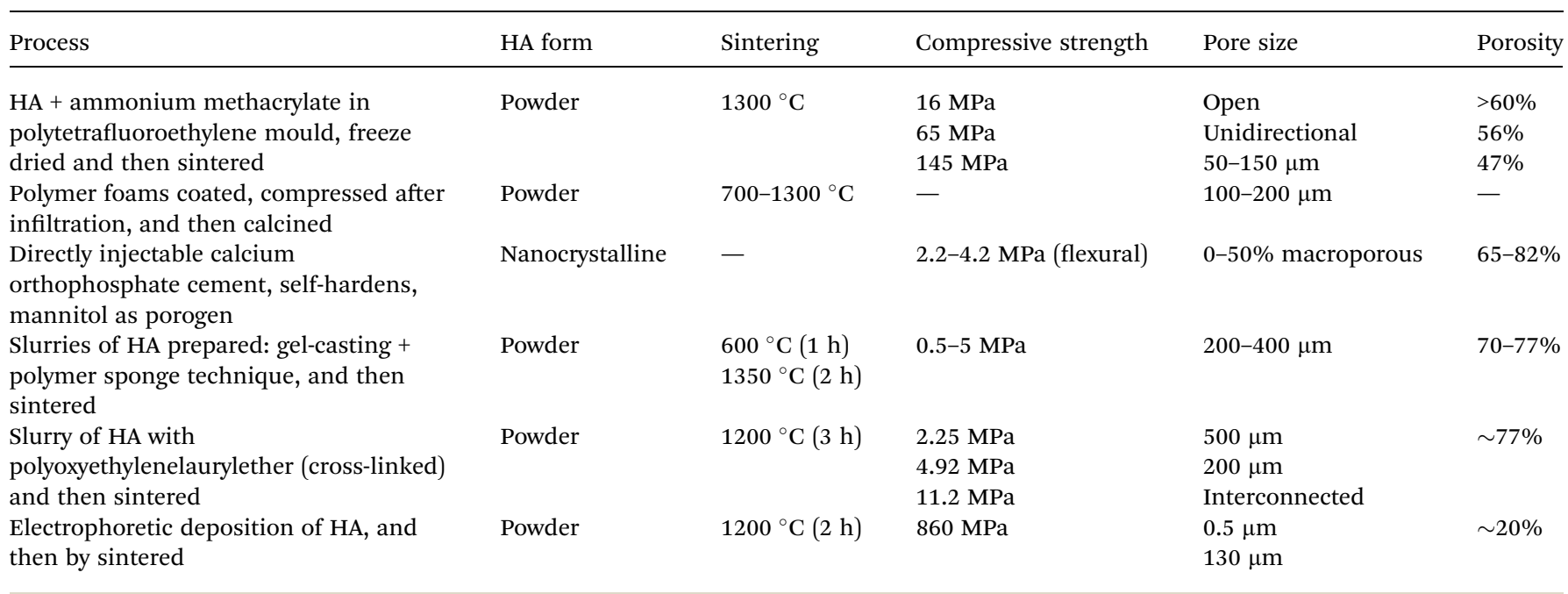

material). ${ }^{133}$ In addition, excessive hardness of the bioceramic implanting materials will lead to wearing of the bone. HA-based bioceramics can be fabricated by various methods according to the requirements of the experiment or implanting site (Table 5). For the preparation of an implanting material with high tensile strength, sintered (dense) (Fig. 13(a)) ceramics (bending strength 38-250 $\mathrm{MPa}$, compressive strength 120-900 MPa, and tensile strength $300 \mathrm{MPa}$ ), are used instead of porous ceramics (bending strength 2-11 MPa, compressive strength 2-100 MPa, and tensile strength $\sim 3 \mathrm{MPa}$ (ref. 125 and 134)). Porous ceramics (Fig. 13(a)) with interconnected pores fabricated by burning the organic materials ${ }^{\mathbf{1 3 5 , 1 3 6}}$ are mainly used in drug delivery, bone in growth, bone fixation, etc. ${ }^{\mathbf{1 3 5 , 1 3 7 - 1 3 9}}$ Research is growing on the preparation of bio-ceramics to mimic natural bone cement. For that purpose, various reinforcing agents such as metals, nanoparticles, and fibers have been tested. However, adding these materials may sometimes affect the biocompatibility of HA. To overcome this issue, Ahn et al. fabricated HAbased $\mathrm{Zr}$ bioceramic materials with a fine structure and enhanced mechanical properties, and suggested that it could be used both in dental and orthopedic implanting materials. ${ }^{\mathbf{1 4 0}}$ Yamashita et al. used an electrospinning technique to control the morphology of HA-based ceramic materials. Using this technique, the HA crystals on the negatively charged surface of the HA ceramic were grown in simulated body fluid. ${ }^{141}$ Several
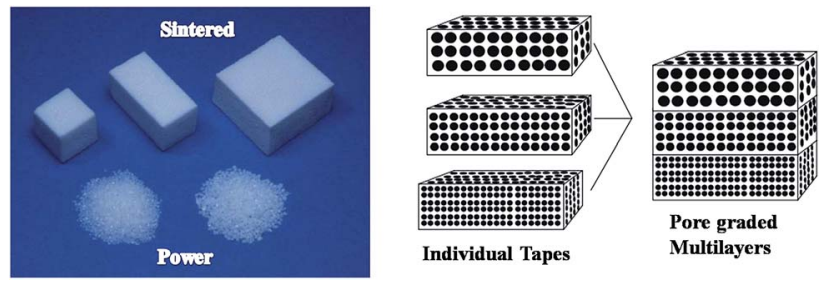

Fig. 13 Example of sintered $\mathrm{HA}$ used as an artificial bone substitute (reproduced with permission from MDPI) ${ }^{146}$ and graded porous HA materials using tape-casting and lamination (reproduced with permission from MDPI). ${ }^{147}$ research groups have been studying various systems to fabricate an ideal scaffold, and thus, they have been testing different materials such as HA/collagen, ${ }^{126,142}$ HA/PLGA and HA/PLA, ${ }^{123,143}$ HA/PMMA, among others. ${ }^{127,144}$ However, despite the recent advances, there is a necessity for more research to prepare an infection-free implanting material with sufficient mechanical strength.

\section{Future prospects}

With the advances in materials science and nanotechnology, new materials have been regularly fabricated for several purposes. HA is used as an orthopedic implant, coating on metallic materials, and drug delivery carrier. Substantial advances have been made regarding our knowledge and understanding of cellular reactions to $\mathrm{HA}$ and related ceramics. However, HA still has limited applications in loadbearing systems. Hence, researchers are now focusing on the development of materials that could bear loads (sufficient mechanical strength). They are using various strategies to combine HA and related calcium phosphate materials with natural polymers to fabricate composite materials with mechanical strength, elasticity, and toughness similar to that of bone. Moreover, scientists are also facing a challenge to develop strategies to avoid possible infections. Research has been advancing in this direction using nanotechnology. HA coating is also playing a vital part in the enhancement of bone formation, as these provide an osteoconductive and osteoinductive approach. The biological properties may be amplified further by grafting growth factors and other useful molecules to HA to fabricate a real osteoinductive platform. However, limitations related to the necessity and effectiveness of HA coatings in different anatomic sites, robustness of HA coatings to withstand physiological loads, and third-body wear by HA particles, restrict its application. Further research to answer these questions will improve the mechanical and biologic aspects of HA-based implants and optimize their safety and efficiency. 


\section{Acknowledgements}

This research was supported by the Basic Science Research Program through the National Research Foundation of Korea (NRF) funded by the Ministry of Education (No. 2016R1D1A1A9918166).

\section{References}

1 W. Gu, C. Wu, J. Chen and Y. Xiao, Int. J. Nanomed., 2013, 8, 2305-2317.

2 V. Vasilev, I. Andreeff, T. Sokolov and N. Vidinov, Archives of Orthopaedic and Traumatic Surgery, 1986, 106, 232-237.

3 S. I. A. Razak, N. Sharif and W. Rahman, Int. J. Basic Appl. Sci., 2012, 12, 31-49.

4 V. Uskoković and D. P. Uskoković, J. Biomed. Mater. Res., Part B, 2011, 96, 152-191.

5 Z. Zhang, Y.-W. Zhang and H. Gao, Proc. R. Soc. B, 2010, 278, 519-525.

6 J.-Y. Rho, L. Kuhn-Spearing and P. Zioupos, Med. Eng. Phys., 1998, 20, 92-102.

7 H. Cao, L. Zhang, H. Zheng and Z. Wang, J. Phys. Chem. C, 2010, 114, 18352-18357.

8 L. J. Cummings, M. A. Snyder and K. Brisack, in Methods in Enzymology, ed. R. B. Richard and P. D. Murray, Academic Press, 2009, vol. 463, pp. 387-404.

9 S. Koutsopoulos, J. Biomed. Mater. Res., 2002, 62, 600-612.

10 A. Haider, K. C. Gupta and I.-K. Kang, Nanoscale Res. Lett., 2014, 9, 314.

11 T. J. White and Z. Dong, Acta Crystallogr., Sect. B: Struct. Sci., 2003, 59, 1-16.

12 N. H. de Leeuw, Chem. Commun., 2001, 1646-1647.

13 S. Xu, J. Long, L. Sim, C. H. Diong and K. K. Ostrikov, Plasma Processes Polym., 2005, 2, 373-390.

14 P. W. Brown and B. Constantz, Hydroxyapatite and related materials, CRC press, 1994.

15 N. Ignjatovic, E. Suljovrujic, J. Budinski-Simendic, I. Krakovsky and D. Uskokovic, J. Biomed. Mater. Res., Part $B, 2004,71,284-294$.

16 M. Ashok, S. N. Kalkura, N. M. Sundaram and D. Arivuoli, J. Mater. Sci.: Mater. Med., 2007, 18, 895-898.

17 D. Janackovic, I. Jankovic, R. Petrovic, L. KosticGvozdenovic, S. Milonjic and D. Uskokovic, in 15th International Symposium on Ceramics in Medicine, ed. B. BenNissan, D. Sher and W. Walsh, Sydney, Australia, 2002, pp. 437-440.

18 Y. Wu, L. L. Hench, J. Du, K. L. Choy and J. Guo, J. Am. Ceram. Soc., 2004, 87, 1988-1991.

19 E. San Thian, Z. Ahmad, J. Huang, M. J. Edirisinghe, S. N. Jayasinghe, D. C. Ireland, R. A. Brooks, N. Rushton, W. Bonfield and S. M. Best, Biomaterials, 2008, 29, 18331843.

$20 \mathrm{M}$. Wei and J. Evans-Freeman, Synthesis and characterisation of hydroxyapatite and fluorapatite, in Key Engineering Materials, Trans Tech Publ, 2001, pp. 35-38.
21 N. Ignjatovic, E. Suljovrujic, J. Budinski-Simendic, I. Krakovsky and D. Uskokovic, J. Biomed. Mater. Res., Part $B$, 2004, 71, 284-294.

22 A. Lak, M. Mazloumi, M. S. Mohajerani, S. Zanganeh, M. R. Shayegh, A. Kajbafvala, H. Arami and S. K. Sadrnezhaad, J. Am. Ceram. Soc., 2008, 91, 35803584 .

23 J. Liu, K. Li, H. Wang, M. Zhu and H. Yan, Chem. Phys. Lett., 2004, 396, 429-432.

24 H. G. Zhang and Q. Zhu, Mater. Lett., 2005, 59, 3054-3058.

25 S. Sasikumar and R. Vijayaraghavan, Ceram. Int., 2008, 34, 1373-1379.

26 G. C. Koumoulidis, A. P. Katsoulidis, A. K. Ladavos, P. J. Pomonis, C. C. Trapalis, A. T. Sdoukos and T. C. Vaimakis, J. Colloid Interface Sci., 2003, 259, 254-260.

27 S. Bose and S. K. Saha, Chem. Mater., 2003, 15, 44644469.

28 S. Sarda, M. Heughebaert and A. Lebugle, Chem. Mater., 1999, 11, 2722-2727.

29 Y. Gao, MRS Online Proceedings Library Archive, 1998, vol. 550.

30 K. Teshima, S. Lee, M. Sakurai, Y. Kameno, K. Yubuta, T. Suzuki, T. Shishido, M. Endo and S. Oishi, Cryst. Growth Des., 2009, 9, 2937-2940.

31 Y. Cai and R. Tang, J. Mater. Chem., 2008, 18, 3775-3787.

32 V. Uskoković, Curr. Nanosci., 2009, 5, 372-389.

33 D. G. Shchukin, G. B. Sukhorukov and H. Möhwald, Chem. Mater., 2003, 15, 3947-3950.

34 Y. Cai, Y. Liu, W. Yan, Q. Hu, J. Tao, M. Zhang, Z. Shi and R. Tang, J. Mater. Chem., 2007, 17, 3780-3787.

35 K. K. Perkin, J. L. Turner, K. L. Wooley and S. Mann, Nano Lett., 2005, 5, 1457-1461.

36 S. Kehoe, M. Ardhaoui and J. Stokes, J. Mater. Eng. Perform., 2011, 20, 1423-1437.

37 M. Ferraz, F. Monteiro and C. Manuel, J. Appl. Biomater. Biomech., 2004, 2, 74-80.

38 S. Pramanik, A. K. Agarwal, K. Rai and A. Garg, Ceram. Int., 2007, 33, 419-426.

39 K. Agrawal, G. Singh, D. Puri and S. Prakash, J. Miner. Mater. Charact. Eng., 2011, 10, 727-734.

40 S. Y. Chung, Y.-M. Kim, J.-G. Kim and Y.-J. Kim, Nat. Phys., 2009, 5, 68-73.

41 G. M. Cunniffe, F. J. O'Brien, S. Partap, T. J. Levingstone, K. T. Stanton and G. R. Dickson, J. Biomed. Mater. Res., Part A, 2010, 95, 1142-1149.

42 P. Wang, C. Li, H. Gong, X. Jiang, H. Wang and K. Li, Powder Technol., 2010, 203, 315-321.

43 E. Bouyer, F. Gitzhofer and M. Boulos, J. Mater. Sci.: Mater. Med., 2000, 11, 523-531.

44 C. Kothapalli, M. Wei, A. Vasiliev and M. T. Shaw, Acta Mater., 2004, 52, 5655-5663.

45 M. Manoj, R. Subbiah, D. Mangalaraj, N. Ponpandian, C. Viswanathan and a. K. Park, Nanobiomedicine, 2015, 2, 2-11.

46 M. Cao, Y. Wang, C. Guo, Y. Qi and C. Hu, Langmuir, 2004, 20, 4784-4786. 
47 N. Esmaeilian Tari and M. M. K. Motlagh, Bioinorg. Chem. Appl., 2009, 2009, 3-6.

48 E. M. Rivera-Muñoz, Hydroxyapatite-Based Materials: Synthesis and Characterization, 2011.

49 A. Haider, K. C. Gupta and I.-K. Kang, BioMed Res. Int., 2014, 2014, 11.

50 H. W. Kim, H.-H. Lee and J. C. Knowles, J. Biomed. Mater. Res., Part A, 2006, 79, 643-649.

$51 \mathrm{H}$. Tanaka, T. Watanabe, M. Chikazawa, K. Kandori and T. Ishikawa, J. Colloid Interface Sci., 1999, 214, 31-37.

52 H. Tanaka, M. Futaoka, R. Hino, K. Kandori and T. Ishikawa, J. Colloid Interface Sci., 2005, 283, 609-612.

53 A. C. Maurin, P. M. Chavassieux, E. Vericel and P. J. Meunier, Bone, 2002, 31, 260-266.

54 H. W. Kim, J. Biomed. Mater. Res., Part A, 2007, 83, 169177.

55 S. Haider, S.-Y. Park, K. Saeed and B. L. Farmer, Sens. Actuators, B, 2007, 124, 517-528.

56 S. Shimabayashi and T. Uno, Hydroxyapatite biopolymer interactions, Polymeric Materials Encyclopedia, ed. J. C. Salamona, CRC Press, Boca Raton, Florida, 1998, vol. 5, pp. 652-654, ISBN 9780849322266 - CAT\# 2226.

57 A. Dupraz, J. De Wijn and K. De Groot, J. Biomed. Mater. Res., 1996, 30, 231-238.

58 J.-L. Zhao, T. Fu, Y. Han and K.-W. Xu, Mater. Lett., 2004, 58, 163-168.

59 C. Santos, R. L. Clarke, M. Braden, F. Guitian and K. W. M. Davy, Biomaterials, 2002, 23, 1897-1904.

60 M. Hashimoto, H. Takadama, M. Mizuno and T. Kokubo, Mater. Res. Bull., 2006, 41, 515-524.

61 Z. Hong, X. Qiu, J. Sun, M. Deng, X. Chen and X. Jing, Polymer, 2004, 45, 6699-6706.

62 Z. Hong, P. Zhang, C. He, X. Qiu, A. Liu, L. Chen, X. Chen and X. Jing, Biomaterials, 2005, 26, 6296-6304.

63 A. Haider, S. Kim, M.-W. Huh and I.-K. Kang, BioMed Res. Int., 2015, 2015, 12.

64 H. Tanaka, M. Futaoka and R. Hino, J. Colloid Interface Sci., 2004, 269, 358-363.

65 H. W. Choi, H. J. Lee, K. J. Kim, H.-M. Kim and S. C. Lee, J. Colloid Interface Sci., 2006, 304, 277-281.

66 S. C. Lee, H. W. Choi, H. J. Lee, K. J. Kim, J. H. Chang, S. Y. Kim, J. Choi, K.-S. Oh and Y.-K. Jeong, J. Mater. Chem., 2007, 17, 174-180.

67 C. Damia and P. Sharrock, Mater. Lett., 2006, 60, 3192-3196.

68 Q. Liu, J. R. de Wijn and C. A. van Blitterswijk, Biomaterials, 1997, 18, 1263-1270.

69 J. Wei, A. Liu, L. Chen, P. Zhang, X. Chen and X. Jing, Macromol. Biosci., 2009, 9, 631-638.

70 S. Deb, L. Aiyathurai, J. A. Roether and Z. B. Luklinska, Biomaterials, 2005, 26, 3713-3718.

71 Y. Dai, M. Xu, J. Wei, H. Zhang and Y. Chen, Appl. Surf. Sci., 2012, 258, 2850-2855.

72 I. Sheikh and Y. Dahman, in Nanobiomaterials in Hard Tissue Engineering, William Andrew Publishing, 2016, pp. 33-62.

73 L. T. Bang, B. D. Long and R. Othman, Sci. World J., 2014, 2014, 9.
74 Z. Zhao, M. Espanol, J. Guillem-Marti, D. Kempf, A. DiezEscudero and M. P. Ginebra, Nanoscale, 2016, 8, 1595-1607.

75 S. Bodhak, S. Bose and A. Bandyopadhyay, Mater. Sci. Eng., C, 2011, 31, 755-761.

76 Y. Li, J. Widodo, S. Lim and C. P. Ooi, J. Mater. Sci., 2012, 47, 754-763.

77 S. Bose, G. Fielding, S. Tarafder and A. Bandyopadhyay, Trends Biotechnol., 2013, 31, DOI: 10.1016/ j.tibtech.2013.1006.1005.

78 J. J. Gray, Curr. Opin. Struct. Biol., 2004, 14, 110-115.

79 T. Kawasaki, S. Takahashi and K. Ideda, Eur. J. Biochem., 1985, 152, 361-371.

80 T. Kawasaki, K. Ikeda, S. Takahashi and Y. Kuboki, Eur. J. Biochem., 1986, 155, 249-257.

81 S. Zhang, Hydroxyapatite Coatings for Biomedical Applications, CRC Press, 2013.

82 X. Chen, Q. Wang, J. Shen, H. Pan and T. Wu, J. Phys. Chem. C, 2007, 111, 1284-1290.

83 W. J. Shaw, A. A. Campbell, M. L. Paine and M. L. Snead, J. Biol. Chem., 2004, 279, 40263-40266.

84 K. Kandori, S. Oda, M. Fukusumi and Y. Morisada, Colloids Surf., B, 2009, 73, 140-145.

85 J. M. Thomann, M. J. Mura, S. Behr, J. D. Aptel, A. Schmitt, E. F. Bres and J. C. Voegel, Colloids Surf., 1989, 40, 293-305.

86 T. N. Tram Do, W.-H. Lee, C.-Y. Loo, A. V. Zavgorodniy and R. Rohanizadeh, Ther. Delivery, 2012, 3, 623-632.

87 K. Tan, P. Cheang, I. A. W. Ho, P. Y. P. Lam and K. M. Hui, Gene Ther., 2007, 14, 828-835.

88 H. Liu, F. Chen, P. Xi, B. Chen, L. Huang, J. Cheng, C. Shao, J. Wang, D. Bai and Z. Zeng, J. Phys. Chem. C, 2011, 115, 18538-18544.

89 K. Deshmukh, M. M. Shaik, S. R. Ramanan and M. Kowshik, ACS Biomater. Sci. Eng., 2016, 2, 1257-1264.

90 M. H. Uddin, A. Nakahira, M. Okazaki, T. Sohmura and T. Matsumoto, Biomimetic fabrication of apatite related biomaterials, INTECH Open Access Publisher, 2010.

$91 \mathrm{M}$. Okada and T. Matsumoto, Japanese Dental Science Review, 2015, 51, 85-95.

92 J. Kirkham, S. J. Brookes, R. C. Shore, S. R. Wood, D. A. Smith, J. Zhang, H. Chen and C. Robinson, Curr. Opin. Colloid Interface Sci., 2002, 7, 124-132.

93 A. Rimola, M. Corno, C. M. Zicovich-Wilson and P. Ugliengo, J. Am. Chem. Soc., 2008, 130, 16181-16183.

94 J. N. Yewle, Y. Wei, D. A. Puleo, S. Daunert and L. G. Bachas, Biomacromolecules, 2012, 13, 1742-1749.

95 Z. Li, Z. Liu, M. Yin, X. Yang, Q. Yuan, J. Ren and X. Qu, Biomacromolecules, 2012, 13, 4257-4263.

96 J. S. Son, Y.-A. Choi, E.-K. Park, T.-Y. Kwon, K.-H. Kim and K.-B. Lee, J. Biomed. Mater. Res., Part B, 2013, 101, 247-257.

97 A.-R. Ibrahim, X. Li, Y. Zhou, Y. Huang, W. Chen, H. Wang and J. Li, Int. J. Mol. Sci., 2015, 16, 7960.

98 K.-W. Lee, C.-M. Bae, J.-Y. Jung, G.-B. Sim, T. R. Rautray, H.-J. Lee, T.-Y. Kwon and K.-H. Kim, J. Biomed. Mater. Res., Part B, 2011, 98, 395-407.

99 S. Loo, T. Moore, B. Banik and F. Alexis, Curr. Pharm. Biotechnol., 2010, 11, 333-342. 
100 S. Koocheki, S. S. Madaeni and P. Niroomandi, Int. J. Nanomed., 2011, 6, 825-833.

101 Y.-H. Yang, C.-H. Liu, Y.-H. Liang, F.-H. Lin and K. C. W. Wu, J. Mater. Chem. B, 2013, 1, 2447-2450.

102 S. S. Syamchand and G. Sony, Microchim. Acta, 2015, 182, 1567-1589.

103 A. G. Gristina, Science, 1987, 237, 1588-1595.

104 E. M. Hetrick and M. H. Schoenfisch, Chem. Soc. Rev., 2006, 35, 780-789.

105 S. B. Goodman, Z. Yao, M. Keeney and F. Yang, Biomaterials, 2013, 34, 3174-3183.

106 J. C. Yu, W. Ho, J. Lin, H. Yip and P. K. Wong, Environ. Sci. Technol., 2003, 37, 2296-2301.

107 K. De Groot, R. Geesink, C. P. A. T. Klein and P. Serekian, J. Biomed. Mater. Res., 1987, 21, 1375-1381.

108 J. C. Odekerken, T. J. Welting, J. J. Arts, G. Walenkamp and P. J. Emans, Modern surface engineering treatments, InTech, New York, 2013, pp. 45-73.

109 J. He, T. Huang, L. Gan, Z. Zhou, B. Jiang, Y. Wu, F. Wu and Z. Gu, J. Biomed. Mater. Res., Part A, 2012, 100, 1706-1715.

110 R. G. T. Geesink, K. De Groot and C. P. A. T. Klein, J. Bone Jt. Surg., 1988, 70, 17-22.

111 E. C. D. S. Rigo, J. Marchi, A. H. D. A. Bressiani and J. C. Bressiani, Mater. Res., 2008, 11, 47-50.

112 R. Z. LeGeros, Clin. Orthop. Relat. Res., 2002, 395, 81-98.

113 K. A. van de Putte and M. R. Urist, Clin. Orthop. Relat. Res., 1965, 40, 257-270.

114 M. R. Urist, Science, 1965, 150, 893-899.

115 M. R. Urist, B. F. Silverman, K. Buring, F. L. Dubuc and J. M. rosenberg, Clin. Orthop. Relat. Res., 1967, 243-283.

116 R. K. Kulkarni, E. G. Moore, A. F. Hegyeli and F. Leonard, J. Biomed. Mater. Res., 1971, 5, 169-181.

117 P. Zhang, Z. Hong, T. Yu, X. Chen and X. Jing, Biomaterials, 2009, 30, 58-70.

118 C. M. Flahiff, A. S. Blackwell, J. M. Hollis and D. S. Feldman, J. Biomed. Mater. Res., 1996, 32, 419-424.

119 S. Higashi, T. Yamamuro, T. Nakamura, Y. Ikada, S.-H. Hyon and K. Jamshidi, Biomaterials, 1986, 7, 183-187.

120 J. Zhao, L. Guo, X. Yang and J. Weng, Appl. Surf. Sci., 2008, 255, 2942-2946.

121 A. S. Dunn, P. G. Campbell and K. G. Marra, J. Mater. Sci.: Mater. Med., 2001, 12, 673-677.

122 Y.-S. Shin, J. S. Borah, A. Haider, S. Kim, M.-W. Huh and I.-K. Kang, J. Nanomater., 2013, 2013, 9.

123 N. Ignjatović, K. Delijić, M. Vukcević and D. Uskoković, $Z$. Metallkd., 2001, 92, 145-149.
124 M. Wang, R. Joseph and W. Bonfield, Biomaterials, 1998, 19, 2357-2366.

125 V. Orlovskii, V. Komlev and S. Barinov, Inorg. Mater., 2002, 38, 973-984.

126 D. Bakoš, M. Soldan and I. Hernandez-Fuentes, Biomaterials, 1999, 20, 191-195.

127 M. Dalby, L. Di Silvio, E. Harper and W. Bonfield, J. Mater. Sci.: Mater. Med., 1999, 10, 793-796.

128 B. M. Chesnutt, A. M. Viano, Y. Yuan, Y. Yang, T. Guda, M. R. Appleford, J. L. Ong, W. O. Haggard and J. D. Bumgardner, J. Biomed. Mater. Res., Part A, 2009, 88, 491-502.

129 A. H. Reddi, Nat. Biotechnol., 1998, 16, 247-252.

130 B. Chevallay and D. Herbage, Med. Biol. Eng. Comput., 2000, 38, 211-218.

131 S. H. Rhee, J. D. Lee and J. Tanaka, J. Am. Ceram. Soc., 2000, 83, 2890-2892.

132 W. Zhang, S. Liao and F. Cui, Chem. Mater., 2003, 15, 32213226.

133 J. Vincent, Biological ceramics in Structural Biomaterials, Princeton University Press, STU - Student edition edn., 3rd edn, 2012, pp. 143-177.

134 S. Dorozhkin, Materials, 2013, 6, 3840-3942.

135 A. Uchida, Y. Shinto, N. Araki and K. Ono, J. Orthop. Res., 1992, 10, 440-445.

136 D.-M. Liu, Ceram. Int., 1998, 24, 441-446.

137 K. Hing, S. Best, K. Tanner, W. Bonfield and P. Revell, J. Mater. Sci.: Mater. Med., 1999, 10, 663-670.

138 W. Paul and C. Sharma, J. Mater. Sci.: Mater. Med., 1999, 10, 383-388.

139 D.-M. Liu, J. Mater. Sci.: Mater. Med., 1997, 8, 227-232.

140 E. S. Ahn, N. J. Gleason, A. Nakahira and J. Y. Ying, Nano Lett., 2001, 1, 149-153.

141 K. Yamashita, N. Oikawa and T. Umegaki, Chem. Mater., 1996, 8, 2697-2700.

142 M. Knepper, S. Moricca and B. Milthorpe, Biomaterials, 1997, 18, 1523-1529.

143 Y. Shikinami and M. Okuno, Biomaterials, 2001, 22, 31973211.

144 K. Watson, K. Tenhuisen and P. Brown, J. Mater. Sci.: Mater. Med., 1999, 10, 205-213.

145 S. Dorozhkin, Materials, 2013, 6, 3840.

146 K. Ishikawa, Materials, 2010, 3, 1138-1155.

147 X. Miao and D. Sun, Materials, 2009, 3, 26-47. 